Florida International University FIU Digital Commons

$12-3-2012$

\title{
Reduced vowel production in American English among Spanish-English bilinguals
}

Emily Byers

Florida International University, ebyer001@fiu.edu

DOI: $10.25148 /$ etd.FI12120519

Follow this and additional works at: https://digitalcommons.fiu.edu/etd

\section{Recommended Citation}

Byers, Emily, "Reduced vowel production in American English among Spanish-English bilinguals" (2012). FIU Electronic Theses and Dissertations. 800.

https://digitalcommons.fiu.edu/etd/800 


\title{
FLORIDA INTERNATIONAL UNIVERSITY
}

Miami, Florida

\section{REDUCED VOWEL PRODUCTION IN AMERICAN ENGLISH AMONG SPANISH-ENGLISH BILINGUALS}

\author{
A thesis submitted in partial fulfillment of the \\ requirements for the degree of \\ MASTER OF ARTS \\ in \\ LINGUISTICS \\ by \\ Emily Byers
}

2012 
To: $\quad$ Dean Kenneth G. Furton

College of Arts and Sciences

This thesis, written by Emily Byers, and entitled Reduced Vowel Production in American English among Spanish-English Bilinguals, having been approved in respect to style and intellectual content, is referred to you for judgment.

We have read this thesis and recommend that it be approved.

Tometro Hopkins

Jean-Robert Cadely

Mehmet Yavas, Major Professor

Date of Defense: November 2, 2012

The thesis of Emily Byers is approved.

Dean Kenneth G. Furton

College of Arts and Sciences

Dean Lakshmi N. Reddi

University Graduate School

Florida International University, 2012 
(C) COPYRIGHT 2012 by Emily Byers

All rights reserved 


\section{ACKNOWLEDGMENTS}

I would like to express my heartfelt gratitude to Dr. Mehmet Yavas for his attention and guidance throughout the duration of this project. His continued support and encouragement has been vital to the successful completion of this thesis.

I would also like to extend sincere thanks to the other two members of my thesis committee, Dr. Tometro Hopkins and Dr. Jean-Robert Cadely, for their valuable advice and commitment of time to this project. I have been extremely fortunate to have the benefit of not only an excellent committee, but also the council of very supportive members of the linguistics faculty.

Special thanks go to Dr. Paulette Johnson for her assistance in processing the results of this study. I also wish to extend a personal thanks to Dr. James Sutton for his generous support of my research and to the English Department for providing an academic environment of the highest quality. 


\section{ABSTRACT OF THE THESIS \\ REDUCED VOWEL PRODUCTION IN AMERICAN ENGLISH AMONG SPANISH- ENGLISH BILINGUALS}

by

Emily Byers

Florida International University, 2012

Miami, Florida

Professor Mehmet Yavas, Major Professor

Prominent views in second language acquisition suggest that the age of L2 learning is inversely correlated with native-like pronunciation (Scovel, 1988; Birdsong, 1999). The relationship has been defined in terms of the Critical Period Hypothesis, whereby various aspects of neural cognition simultaneously occur near the onset of puberty, thus inhibiting L2 phonological acquisition. The current study tests this claim of a chronological decline in pronunciation aptitude through the examination of a key trait of American English - reduced vowels, or "schwas." Groups of monolingual, early bilingual, and late bilingual participants were directly compared across a variety of environments phonologically conditioned for vowel reduction. Results indicate that late bilinguals have greater degrees of difficulty in producing schwas, as expected. Results further suggest that the degree of differentiation between schwa is larger than previously identified and that these subtle differences may likely be a contributive factor to the perception of a foreign accent in bilingual speakers. 


\section{TABLE OF CONTENTS}

CHAPTER

PAGE

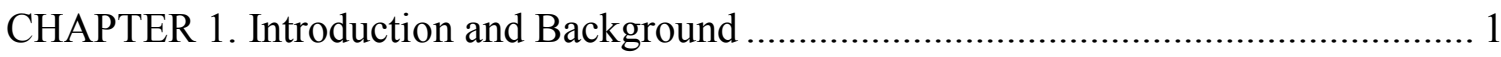

1.1. Vowel Reduction in American English ......................................................... 1

1.1.1. Prototypical phonetic qualities of schwa ......................................... 3

1.1.2. The $[\dot{\mathfrak{t}}] /$ / [ə] distinction in SAE vowel reduction............................ 5

1.1.3. Vowel quality distinctions between plural and possessive

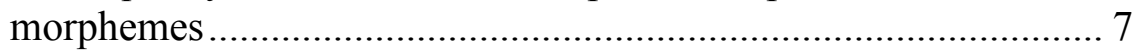

1.1.4. "Targetlessness" in word-internal schwa production ........................ 8

1.1.5. Other properties of schwa - duration and prosody ......................... 11

1.1.6 An introduction to prominent voices in the field of language

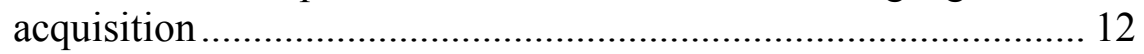

$1.2 \mathrm{CPH}$ : The "Critical Period Hypothesis" ....................................................... 13

1.3 Flege's "Speech Learning Model".............................................................. 19

1.4 Kuhl's "Native Language Magnet Model" ....................................................... 23

1.5 Contemporary Issues in Reduced Vowel Analysis......................................... 25

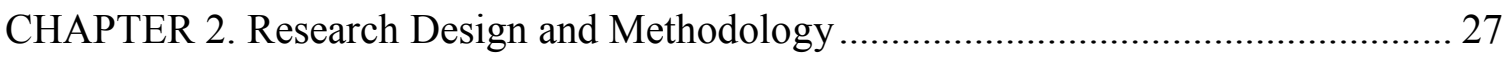

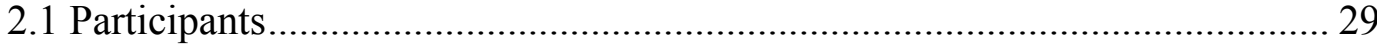

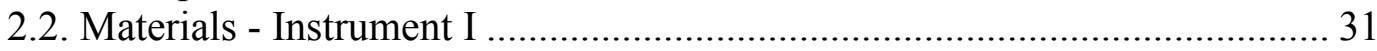

2.2.1. Plural Morpheme ………………………………..................... 31

2.2.2. Possessive Morpheme ..................................................................... 31

2.2.3. Reduced Vowels in Word-Final Position ...................................... 32

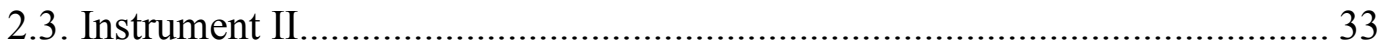

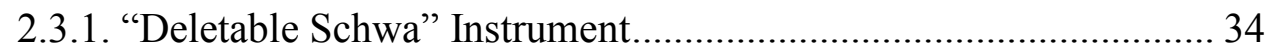

2.3.2. "Non-Deletable Schwa" Instrument .............................................. 35

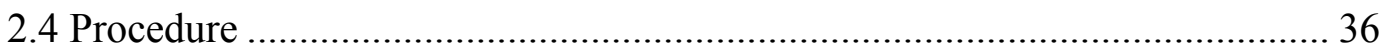

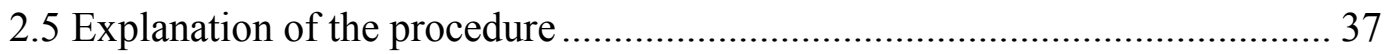

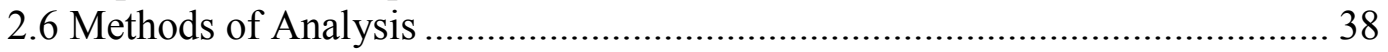

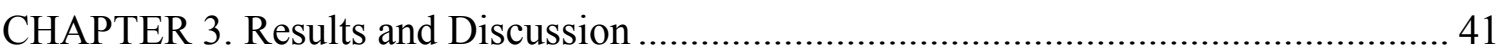

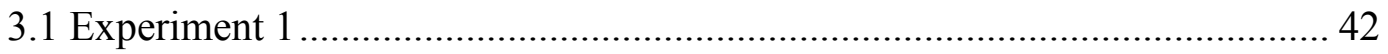

3.1.1. Experiment 1(a) Vowel Qualities Comparison............................... 42

3.1.2. Experiment 1(b) Reduced vowel duration: A cross-group

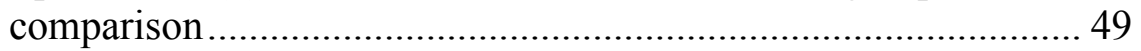

3.1.3 Effects of preceding consonants on vowel duration in wordfinal position ................................................................................. 53

3.1.4. Effects of segmental features on the vowel qualities of reduced vowels in word-final position........................................... 57

3.2. Experiment II

3.2.1. Comparison of reduced vowel lengths in word-internal

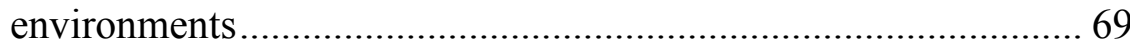

3.2.2. Semantically-related words .......................................................... 72

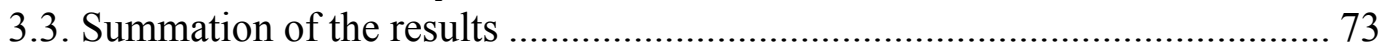




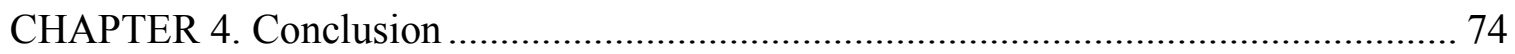

4.1. Theoretical Implications for Reduced Vowel Production ............................. 74

4.1.1. Speech Learning Model .............................................................. 74

4.1.2. Native Language Magnet Model ................................................... 76

4.2 Generalizations regarding L2 reduced vowel production................................ 77

4.2.1. Vowel quality distinctions ............................................................. 77

4.2.2. Variation in schwa duration........................................................... 79

4.2.3. Semantically-related word pairs …………………...................... 80

4.3. Limitations and Extensions.......................................................................... 82

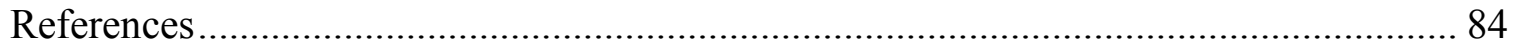

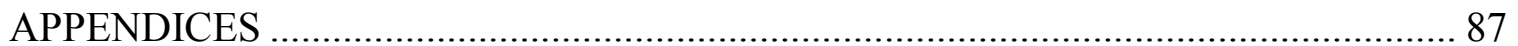




\section{LIST OF FIGURES}

FIGURE

PAGE

Figure 1.2.a Timeline of the relationship between AOA and linguistic competency ....14

Figure 3.1.a Across-groups comparison of F1 values in plural, possessive and word-final environments....

Figure 3.1.b Mean duration for schwa in CV\# position in monolinguals ......................54

Figure 3.1.c Mean duration for schwa in CV\# position in early bilinguals ...................55

Figure 3.1.d Mean duration for schwa in CV\# position in late bilinguals ....................56

Figure 3.1.e Across-groups comparison of F1 values to post-labial CV\# environments

Figure 3.1.f Across-groups comparison of F1 values to post-coronal CV\# environments

Figure 3.1.g Across-groups comparison of F1 values of post-dorsal CV\# environments.

Figure 3.1.h Descriptive statistics of F2-F1 positioning across groups

Figure 3.1.i Comparison of the position of schwa in CV\# position among monolinguals

Figure 3.1.j Comparison of the position of schwa in CV\# position among early bilinguals.

Figure 3.1.k Comparison of the position of schwa in CV\# position among early bilinguals.

Figure 3.1.1 Across-groups comparison of the average values among three places of articulation

Figure 3.2.a Across-groups comparison of duration in deletable and nondeletable schwas. .70

Figure 4.2.a Prototypical F1 and F2 values for SAE vowels .78 


\section{LIST OF TABLES}

TABLE

PAGE

Table 3.1.a Pairwise comparison of F1 values across monolinguals ..........................42

Table 3.1.b Pairwise comparison of F1 values across early bilinguals........................43

Table 3.1.c Pairwise comparison of F1 values across late bilinguals ........................44

Table 3.1.d Mean values of F2-F1 for monolinguals, early bilinguals, and late

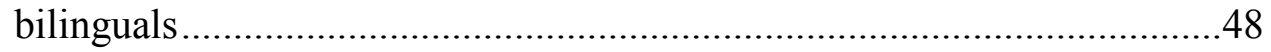

Table 3.1.e Pairwise comparison of average durations in monolingual speakers .......49

Table 3.1.f Pairwise comparison of average durations in early bilinguals..................51

Table 3.1.g Pairwise comparison of average durations in late bilinguals ....................52

Table 3.1.h Across-categories comparison of word-final vowels in late bilinguals

Table 3.2.a Comparison of deletable and nondeletable vowel durations across populations ................................................................................ 71

Table 3.2.b Paired sample T-tests of semantically-related word pairs .......................73 


\section{LIST OF SYMBOLS}

\section{SYMBOL}

/ 1

[]

C

V

\#

ว/^

$\dot{\dagger}$

$\varepsilon$

aI

ว

I

y

ð

1

$æ$
DESCRIPTION

Indicates Phoneme

Indicates Phonetic Representation

Consonant

Vowel

Indicates Word Boundary

Mid Central Lax Unrounded Vowels

High Central Lax Unrounded Vowel

Mid Front Lax Unrounded Vowel

Diphthong Moving from Low Back to High Front Vowel

Mid Back Lax Rounded Vowel

High Front Lax Unrounded Vowel

Velar Nasal Consonant

Voiced Interdental Fricative Consonant

Rhotic Retroflex "r" Consonant

Low Front Lax Unrounded Vowel

Low Back Tense Unrounded Vowel

Voiceless Dental Stop Consonant 


\section{CHAPTER 1. Introduction and Background}

\subsection{Vowel Reduction in A merican English}

Schwa production is a frequently occurring phonological process in American English which results from the neutralization of multiple vowel quality contrasts (Chomsky and Halle, 1968). The process of vowel reduction in stress-timed languages is rule-governed in that it is restricted to unstressed syllables, which may then undergo a secondary phonological process of deletion in selected environments. Fokes (1993) targets the rhythm of a language, particularly the intervals at which stressed beats fall, as a primary factor in determining which vowels are candidates for reduction. Schwas are distinct from what are typically classified as "fast speech" reductions (see Dalby, 1986) where full vowels experience a centralization in both their height and backness features (and can also be optionally deleted) as a result of a rapid speech rhythm, subsequently rendering reduced vowels in both content and function words as in the following examples:

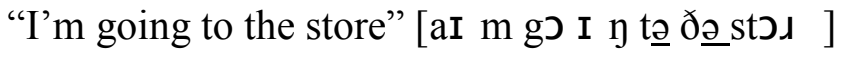

"What do you mean?" [w $\square$ də ju min]

In typical conversation, as in the aforementioned examples, a speaker strives to produce utterances which are sufficiently intelligible to the hearer while maximizing economy in the production (Harrington, 2010). These schwa productions are more likely to occur when the discourse level is informal, particularly when a speaker feels it is unnecessary to pay special attention to clarity of speech. A further contributive factor to the 
production of schwas in fast speech may be the statistical frequency with which the target word is used in the language. Wright (2003) theorizes that the vowels of "hard" words are pronounced in an expanded vowel space as compared with those of "easy" words. The "hard"/ "easy" distinction is correlated with a language's neighborhood density, whereby words possessing a high value neighborhood density exist alongside many other words containing obvious phonemic similarities. "Easy" words, therefore, meet the requirements of occurring frequently in the language while possessing a low neighborhood density - thus decreasing the likelihood that the target word will be confused with another (see Harrington, 2010). Fast-speech schwa productions, however, should not be classified alongside the "definite" ${ }^{11}$ representation of schwa in the American vowel system, which is the focus of the current study, as definite schwa production elicits the reduction of a full vowel at any speech tempo (i.e., "Carolina" [ked ə laI nə], “christening" [kג I sənI $\mathrm{\eta}]$ ).

Through systematic analysis of the acoustic properties of schwa production in monolinguals, the current study addresses the question: How is this mid-central lax vowel produced in the oral cavity? As chapters two and three will demonstrate, measurements of the features "vowel height" and "backness" of schwas across a variety of phonologically-conditioned environments provide a framework of average schwa values for specific phonological settings. It is necessary from the onset to introduce comprehensive background information regarding generalizations that can be made about the prototypical phonetic characteristics of schwa in order to provide a basic

${ }^{11}$ This term is often used in the literature to indicate a phonological process as contrasted with hypoarticulation of a vowel. 
understanding of the perceptual and articulatory challenges that Spanish-English bilinguals face when presented with target schwa, as compared with the Spanish vowel system.

\subsubsection{Prototypical phonetic qualities of schwa}

As is to be expected, properties of schwa (such as duration and vowel qualities) show high variation among different demographics. Factors such as age, gender, and regional dialect all contribute to markedly different sound productions. Other factors which affect schwa production include the method in which constructions are elicited (i.e., reading a sentence vs. oral interviews) and even the level of intimacy between speaker and listener. Though these social factors certainly create high levels of acoustic variation in reduced vowel production, both between speakers and within the same speaker across utterances, it is not impossible to make legitimate generalizations regarding the phonetic characteristics of schwa.

In a monolingual Standard American English speaker (SAE hereafter), a schwa is the result of the movement of a vowel away from the periphery into the underutilized central vowel space. Chomsky and Halle (1968) consider these contrasts to be "neutralized" because the effect results in the features [- high, - low] and [- front, - back]. Table 1.1.a provides an illustration of the position of schwa in the vowel inventory of Standard American English. 


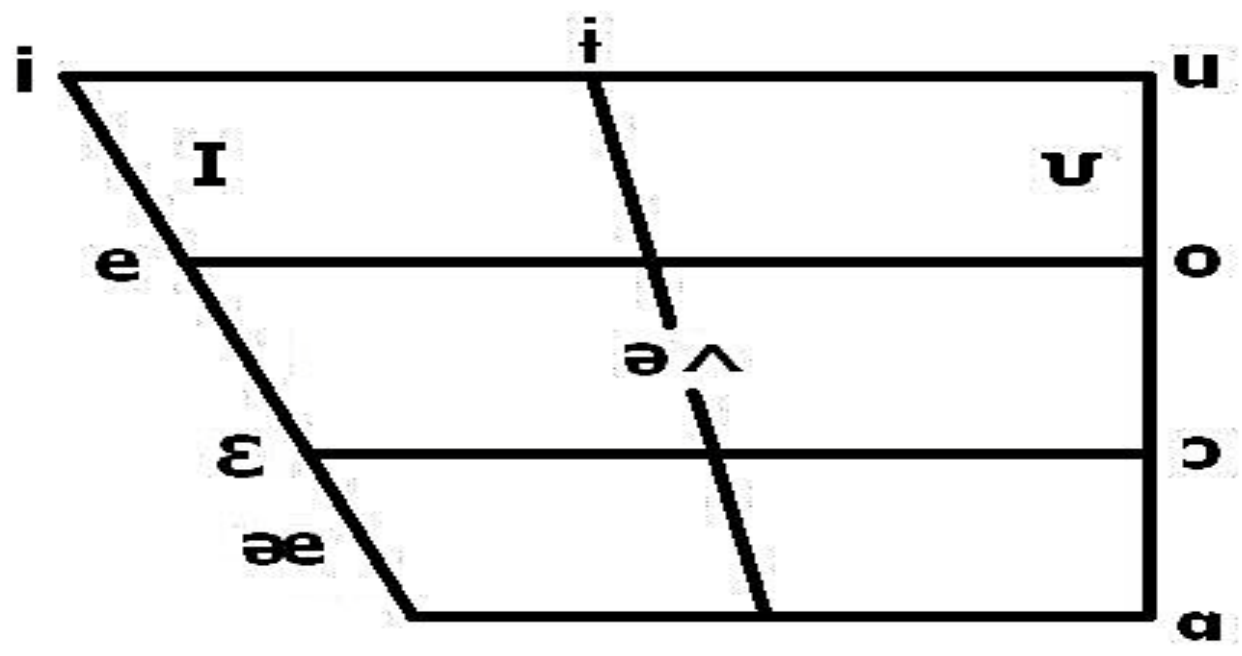

Source: www.mnsu.edu/phonetics/SAE

Schwa is unique among the vowels of SAE because, unlike $/ \wedge /$, it is not phonemic in nature. That is, while / $\wedge$ / is able to contrast minimally with other vowels (/bæt/ vs. $/ b \wedge t /)$, schwa does not. The unconscious nature of the vowel reduction leaves speakers without a mental representation for [ə], as their L1 inventory leads the untrained ear to believe that it is actually peripheral vowels which are being produced. The contrast in perception and production becomes increasingly problematic for L2 learners whose L1 vowel inventories contain neither central vowels, nor reduction processes, as the result is often peripheral vowel substitution in lieu of the target phoneme. Table 1.1.b illustrates the Spanish vowel inventory, including the allophone $[\varepsilon]$ for /e/. 
Table 1.1.b Vowels of Spanish

\begin{tabular}{|c|c|c|}
\hline is & & /u/ \\
\hline \multicolumn{1}{|c|}{$/ \mathrm{e} /$} \\
{$[\varepsilon]$} & & /o/ \\
\hline & & \\
\hline & $/ \mathrm{a} /$ & \\
\hline
\end{tabular}

Sour ce: The Sounds of Spanish: Analysis and Application by R obert Hammond, 1999.

As demonstrated in Table 1.1.b above, the Spanish vowel inventory contains no phonemes within the mid-central or high-central regions. Therefore, L2 target vowels which fall into this otherwise barren region of the oral cavity will be considered reduced in that they fall into a bilingual's "reduced vowel zone." Table 1.1.a is a particularly detailed chart of the SAE vowel system in that it includes both phonemic and allophonic representations which are not always listed in other accounts of the SAE vowel inventory. Of particular interest is the [ $[\dot{\mathfrak{}}] /$ / [ə] distinction, about which there have been studies (see Flemming, 1997, 1999: Hammond 1999) both advocating for, and dismissing, the need for separate transcription symbols for these reduced central vowel sounds.

\subsubsection{The $[\dot{\mathbf{t}}] /[\mathbb{\bigotimes}]$ distinction in SAE vowel reduction}

An issue which is well-established in the literature concerning vowel reduction is the predictive nature of F1 and F2 formants (indicating vowel height and the degree of backness) in environments phonologically conditioned for schwa. Hammond (1999) and Flemming (2009), among others, identify a distinction in the phonetic properties of [ə] and $[\dot{\mathfrak{t}}]$, though their conclusions differ in what should be done regarding transcription and analysis. 
For Hammond, the distinction is of an articulatory nature. He describes "barredi” [ $\dot{\mathfrak{+}}]$ as a high, central, lax, unrounded vowel which is clearly articulated in a higher manner than the mid, central, lax, unrounded vowel transcribed as schwa [ə]; however, Hammond argues for the general acceptability of a "reduced vowel zone." In essence, he argues that since there is nothing contrastive about the $[\dot{\mathfrak{t}}] /[$ ?] distinction, emphasis should be placed upon whether or not the L2 speaker is able to move a peripheral vowel into the otherwise unoccupied central vowel space. Furthermore, it is the case that monolingual speakers may alternate between $[\dot{+}]$ and $[ə]$ depending on whether they are speaking a regional dialect or SAE, thus causing both sounds to be judged as acceptable by native speakers. Therefore, it is the shared opinion of the current study that $[\dot{\mathfrak{t}}]$ and [ə] should both be judged as accurately reduced vowels, occupying the mid-to-high central "reduced vowel zone," with no need to further dissect the zone into central and high-central areas when making acceptability judgments in the analysis. It follows then that the transcription of all reduced vowels as [ə] is acceptable for the binary distinction "reduced/nonreduced" as presented in chapters two and three.

Flemming, however, calls for a distinction in the phonetic transcriptions of midcentral lax [ə] and high-central lax $[\dot{\mathfrak{t}}]$ in order to better match the phonetic properties of these centralized vowels in context. His call for two distinct transcriptional markers is a consequence the fact that reduced vowels in the plural morpheme are impressionistically and instrumentally different from schwas in both the possessive morpheme and wordfinally. It has been observed that these differences in the vowel qualities of "schwa" occur predictably when certain morphemes are compared against other phonological environments. Flemming and Johnson (2007) found that schwas in word-final position 
(i.e., "china" [ $\mathrm{t}$ aI nə], "comma" [k $\square \mathrm{m} ə]$ ) have a relatively consistent mid-central vowel quality. In monolingual speakers, the values of F1 formants (indicating vowel height) in word-final schwas rank consistently higher than those in bound morphemes, indicating that word-final schwa is produced with a lower vowel. In Flemming's (2009) monolingual participants, the average F1 value for word-final schwa was $665 \mathrm{~Hz}$, which is considerably higher than the $500 \mathrm{~Hz}$ that Olive et al. (1993) identified as a standard F1 value for schwa in Standard American English.

According to Flemming et al., the vowel qualities of the plural morpheme $\{-ə z\}$ (as in "places") differ significantly from two other environments containing a schwa nucleus: word-final schwa [ə] and the possessive morpheme $\{-\partial z\}$ (as in "Chris's"), which Flemming concludes is simply the construction of 'word-final schwa $+/ \mathrm{s} /$ '. Though the plural and possessive morphemes are transcribed, and are written in the orthography, identically, Flemming and Johnson (2007) prove that they are not homophonous with regard to vowel quality production. The minimal pair "Rosa's roses," originally noted by Trager and Bloch in 1941 (Flemming and Johnson, 2007), illustrates the failings of general IPA transcriptions to account for the obvious differences in the pronunciations of the aforementioned words. There is certainly an argument to be made that transcribing these sounds as separate symbols would elicit more native-like pronunciations of words than the blanket symbol [ə] is able to represent.

\subsubsection{Vowel quality distinctions between plural and possessive mor phemes}

Flemming and Johnson identify the plural morpheme schwa (as in "roses") as containing a lower F1, thus creating a vowel higher in the vocal tract, than those in possessive morphemes (such as "Rosa's.) Their study concludes that typical values one 
expects to find for the vowel qualities "height" and "backness" in the possessive morpheme $\{-$ zz $\}$ should be expected to mirror those of schwa in word-final endings. Essentially, Flemming and Johnson argue that schwa in the possessive morpheme is in actuality word-final schwa with only the addition of possessive marker $\{-\mathrm{s}\}$ (realized phonetically as [-z]) to differentiate the environment. The testing of this claim, among monolinguals and two bilingual populations, is one of the central focuses of my study. Flemming and Johnson further distinguish schwas in the plural morpheme $\{-$ zz $\}$ from possessive and word-final environments by arguing that reduced vowels in the plural morpheme are more suitably grouped with other word-internal schwas (as in [pri nsi pəl]), which they claim are better represented by $[\dot{\dagger}]$. The claim becomes problematic in view of Flemming's (2009) work concerning the "targetlessness" of wordinternal schwa.

\subsection{4. "Tar getlessness" in word-internal schwa production}

The transparent ability of word-internal schwa to assimilate its vowel qualities to neighboring consonants has led researchers (Kondo 1994; Flemming 2009) to pose the question: Is medial schwa targetless with regard to $\mathrm{F} 1$ and $\mathrm{F} 2$ values? Observations that schwa is articulated closer to the front of the oral cavity in anticipation of a labial sound, or higher in anticipation of an alveolar or palate-alveolar, have fostered the notion that medial reduced vowels may serve as empty place holders, devoid of independent vowel qualities, in word-internal environments. Since 1960's linguists have determined that surrounding consonant environments temper vowel qualities by shifting vowel formants toward more central values (Stevens and House, 1963). These studies report the largest 
effects on F2 values, the measure which indicates the relative front/back position of a vowel in the oral cavity.

More recently, Browman and Goldstein (1990), Kondo (1994) and Flemming (2009) have all conducted empirical studies regarding the question of whether or not reduced vowels exhibit patterns under spectrographic analysis. Specifically, they seek to determine whether schwa's F1 and F2 formants have any predictable target values. Kondo, in particular, cites numerous arguments in favor of the approach that medial schwas, rather than striving for the (F1)500/ (F2)1500/ (F3) $2500 \mathrm{~Hz}$, which are numeric representations of ideal centralization, are actually at the mercy of assimilatory processes caused by segments surrounding the nucleus. According to Kondo's analysis, both vowel centralization and contextual assimilation (caused by adjacent consonants) imply target undershoot ${ }^{2}$. Kondo suggests two possible results stemming from this undershooting: either the vowel will not reach its target and will succumb to the characteristics of surrounding segments or the value will miss its target and instead will find a more centralized value.

The results of Kondo's (1994) experiment indicate that average schwa values for F1 formants did indicate a target vowel height, and that only F2 values (relative front vs. back positioning) could be considered "targetless." These results implies that, while vowels are susceptible to moving forward or backward in the mouth in anticipation of upcoming consonants, the height values remain relatively fixed regardless of the

\footnotetext{
${ }^{2}$ For further information on vowel undershoot see Lindblom's (1963) mathematical model of vowel reduction, which identifies vowel undershoot as a function of vowel duration.
} 
upcoming segment. The debate is far from closed, however, as studies by Hillenbrand et al. (2001) found that consonant environment had only a small, though statistically significant, effect on vowel intelligibility. Browman and Goldstein (1990) provide a supplemental explanation for the inherent variability of medial schwas, whereby certain phonological segments, specifically schwas, may overlap in time (or be "co-produced) in order to reflect the combined articulatory influences of adjacent segments.

A second hypothesis, which is compatible with Kondo's findings, is that a given phonetic unit may be unspecified for a particular dimension. If the target phone is unspecified for a dimension, most likely its F2 value, then it is expected to find that the resultant value under spectrographic analysis will be a result of the movement from the preceding segment, across the valueless nucleus, to the value of the following segment. From a phonological standpoint, Browman and Goldstein are confirming that it is possible to have medial schwa be completely unspecified for tongue position, whereas Kondo suggests that only the feature [+back] may be unspecified.

Flemming (2009) identifies the average F1 (height) values of medial schwa at 428 $\mathrm{Hz}$, which is significantly lower than the values for word-final schwa. Such a discrepancy leads Flemming to support the aforementioned ideas concerning schwa's tendency to assimilate to the surrounding context. Flemming and Johnson (2007) prove this intuition empirically through the use of spectrographic analysis to determine, within their instrument, that higher F2 vowels were found in environments where schwa is adjacent to coronal consonants. In essence, this study found that schwas were produced closer to the front of the mouth when the following consonant contains a [+coronal] feature. 
A final point of interest with regard to the phonetic properties of reduced vowels is raised by Flemming (2009) when he suggests “.... lesser degree of assimilation to context [in addition to the hypothesis that medial schwas undergo assimilation of height, backness, and lip position] still results in raising of low vowels because of assimilation to the narrow constrictions of adjacent consonants" (18). Here Flemming suggests that medial reduced vowels, by virtue of their location inside the root, are physically unable to escape constriction of the narrowed vocal tract should they be encased between obstruents.

\subsubsection{Other properties of schwa - duration and prosody}

In addition to prototypical vowel qualities, there are certain other generalizations about schwa production that, given a sufficient corpora, can be extracted from linguistic studies. Another characteristic which reliably differentiates schwa from peripheral vowels is duration - schwas are much shorter than their full vowel counterparts. Flemming (2009) identifies medial schwa duration at an average of 64 milliseconds for monolingual SAE speakers, compared with 153 milliseconds if the schwa occurs in word-final position. Hammond (1999) identifies the following two part pattern of SAE vowels: 1) Stressed vowels are much longer than unstressed vowels and 2) Unstressed vowels are always realized as reduced vowels. This claim will be examined in the course of the current study.

In addition to generalizations about duration, there are several parameters which researchers have set regarding the vowel qualities of schwa. Olive et al. (1993) identify schwa, produced in a neutral articulatory position, as having formant frequencies which occur at equal intervals positioned at roughly $500 \mathrm{~Hz}$ (F1), $1500 \mathrm{~Hz}$ (F2), and $2500 \mathrm{~Hz}$ 
(F3). In reality, schwa is not often produced in a neutral articulatory position, which results in less than uniform, evenly-spaced formants. This is the result of suprasegmental effects of English. Schwa is not produced in a vacuum, but rather is the result of vowel reduction processes brought forth by patterns of unstressing pretonic and posttonic vowel nuclei, which is predictable in SAE. Even though "ideal" schwas with evenly spaced formants rarely surface in medial position, an identification of the prototypical (ideal) schwa allows researchers to describe L2 speakers' attempts at vowel quality neutralization and identifies areas in which bilingual populations show variation from native speakers - a key contribution to the perception of a foreign accent.

\subsubsection{An introduction to prominent voices in the field of language acquisition}

Flemming and Johnson (2007) have previously identified patterns in vowel quality production which are predictable based on the particular schwa-containing morpheme. True schwas provide testable variables (F1 and F2 values) which allow the current study to make practical application of two theoretical models of language acquisition: Flege's Speech Learning Model (SLM) and Kuhl's Native Language Magnet model (NLM). Both models attempt to account for universal trends in language acquisition apart from a biological reliance on the critical period hypothesis, though neither model denies the existence of a relationship between age of acquisition (AOA) of L1/ L2 and the accuracy of a speaker's phonological output.

Before Flege's SLM and Kuhl's NLM can be discussed in the context of AOA, it is necessary to provide adequate background information regarding the "critical period hypothesis" (CPH hereafter). Section 1.2 describes $\mathrm{CPH}$ in detail, as well as noting the evaluations several prominent experts in the field of L1 and L2 acquisition have made 
regarding the connection between neurobiological processes and phonological inventories. Having established the principle theory $(\mathrm{CPH})$ which Flege and Kuhl refine through their respective speech models, sections 1.3 and 1.4 examine the central tenets of the SLM and NLM, noting that these two theories are functionally compatible in that NLM is primarily concerned with infants' L1 acquisition, whereas SLM works extensively to explain variable success rates in $\mathrm{L} 2$ acquisition, not dismissing age as a crucial predictor of success. Section 1.5 incorporates additional prominent observations (Valdman, 1976; Strange, 2008) regarding the role of perception and production in L2 acquisition - without the inclusion of these voices a thorough review of the literature concerning phonological acquisition would remain incomplete.

\subsection{CPH: The "Critical Period Hypothesis"}

The critical period hypothesis $(\mathrm{CPH})$ has its roots in the observation by Lenneberg (1969) that as humans mature neurologically, the capacity to acquire language is diminished in some way. Even in long-term acquisition of an L2 phonological system, that is, child learners will be expected to exceed adult learners in the mastery of new sounds. Patkowski (1994) formalizes the $\mathrm{CPH}$ as follows:

There is a period, ending around the time of puberty (operationally defined to mean somewhere between the ages of 12 and 15 years), during which it is possible, but not inevitable, for learners to acquire, as an end-product of a naturalistic L2 acquisition process, full native-like fluency in the phonological system of a second language, and after which such a possibility does not exist anymore... (206) 
A central tenet of the $\mathrm{CPH}$ is the notion that the critical period is related to an unspecified neurological change which essentially causes a loss of elasticity in the brain as linguistic sound systems become more "fixed" with regard to language acquisition. This process has also been described by many researchers as a loss of plasticity in the brain which cooccurs with the completion of hemispheric lateralization in the brain (Ioup, 2008).

It is important to reemphasize here that the inability of adults to acquire nativelike L2, as explained by the $\mathrm{CPH}$, refers solely to the pronunciation of native-like phonemes. That is, it is entirely possible to continue developing other outstanding abilities in L2 acquisition such as sophisticated syntax or the ability to acquire a rich and varied lexicon. For the purposes of this study, the term "linguistic output" will be used to refer only to the production of sounds and prosodic features. Figure 1.2.a provides an illustration of the CPH's postulation of the relationship between AOA and L2 linguistic output.

Figure 1.2.a Timeline of the relationship between AoA and linguistic competency

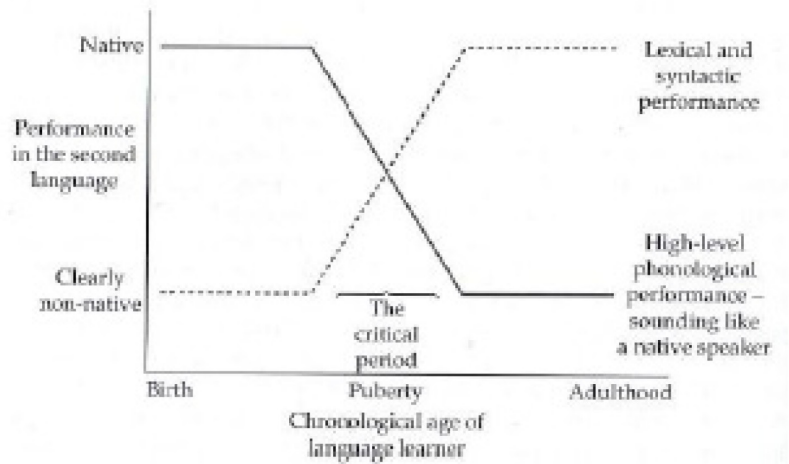

Source: T. Scovel (1988) A Time to Speak: A Psycholinguistic Inquiry into Critical Period for Human Speech from M. Yavas' (2011) Applied English Phonology. 
Lenneburg's observation was originally intended to explain both L1 acquisition and cases involving aphasia; however, noticeable disparities concerning phonetic accuracy in child versus adult L2 learners led researchers to question whether AOA is the determining factor in achieving native-like pronunciation. Best and Tyler (2007) articulate the issue succinctly as follows:

Prior contact with the stimulus language, and position along the trajectory of native or first language (L1) development, converge in some crucial way to shape one's perception of phonetic details and phonological structure in speech. (14)

Traditionally, the "critical period" (or "sensitive period" in some works), after which insurmountable obstacles are faced in L2 phonological acquisition, has been set at the “onset of puberty," typically taken to mean twelve years of age (see Flege, 2005).

Alterations to this critical age include Long's very specific addendum to the $\mathrm{CPH}$ that an L2 is spoken without a foreign accent if learned by the age of six, with a foreign accent if learning begins after age twelve, and with variable success in between (from Birdsong, 1999). Long equates these stages to the maturational stages infants and children progress through in traditional L1 acquisition, which exist independently of cognitive development (see Patkowski, 1994). An insistence that language acquisition is apart from cognitive development may explain why adults may surpass the comparative rate at which children acquire phonology in the very earliest stages of L2 phonological acquisition, and why adults are predicted to outperform children throughout the course of L2 learning with 
regard to the non-phonological aspects of a language (i.e. syntax, lexical acquisition, etc.).

It is true that many people who acquire a second language in adulthood speak with an easily detectable foreign accent. Flege and Hillenbrand (1984) attribute this difference in part to phonetic distances between the speaker's native language and target language, and also to the speaker's ability to manipulate the phonological inventories of the L1 and L2 systems. In these cases, post-critical or "late" bilinguals resort to producing L2 words with at least some of their L1 phonemic inventory in a process known as "equivalence classification," thus creating a complicated interlanguage phonology which causes the "foreign accent" so easily detectable by the untrained ear (see Flege, 1987; Strange and Shafer, 2008). Discourse surrounding issues of perception attempts to explain the mental processes of multilanguage acquisition; however; current perception models acknowledge that AoA remains the most prominent factor in acquiring a native-like sound system.

Patkowski $(1990,1994)$ further advocates for the existence of a critical period; however, he maintains that in order to reliably and legitimately test the $\mathrm{CPH}$ it is imperative that research designs be longitudinal in nature. Long-term studies are required so that adult participants are given time to reach the level of "optimal learning". Specifically, the post- critical period L2 learner must have had both prolonged exposure to the L2 and live in an environment where there is daily use of the L2 in order to have comparable input to that which children receive in their L2 acquisition process (from Birdsong, 1999). 
Patkowski (1994) concedes that IQ, or advanced cognitive development, plays an enthusiastic role in facilitating L2 acquisition during adulthood. Nevertheless, Patkowski maintains that the role played by the input child L2 learners receive, assuming the prototypical child acquires language in a primarily immersive environment, undoubtedly serves children to achieve better rates of fluency and more native-like pronunciation than should be expected of adult L2 learners. Flege has taken issue with the empirical data on which Patkowski's (1990) conclusions rest; however, he acknowledges that the differences in findings could be the result of conflicting methodological considerations or different manners of statistical analysis, rather than a full discrediting of Patkowski's findings. Disagreements concerning methodological approaches may affect the way L2 acquisition data is collected and presented, yet both researchers agree that there is an agerelated period which serves to enhance the capabilities of L2 phonological learning.

While pinpointing AoA as the most prominent factor affecting the degree of foreign accent, Flege has maintained that AoA cannot be the only cause of foreign accent, or a lack thereof, in L2 speakers. Flege et al. (2006) point to the fact that L2 acquisition prior to the end of the critical period does not equip L1 Korean children with native-like pronunciation as proof that $\mathrm{L} 2$ foreign accent can be affected by many factors apart from age. Most prominent among these non-biological factors is the amount of L1 use (Flege et al., 1997), while factors such as L1 proficiency, length of residence, and gender have yet to be adequately proven or invalidated (see Piske et al., 2001).

Since there is more to language acquisition than a simple "pre-critical period"/"post-critical period" binary split, Flege's SLM provides a gradient scale toward native-like productions that is considerably more flexible than biological explanations 
allow for. While acknowledging that age is a, if not the, necessary condition for nativelike phonetic competency, Flege argues that the biological processes needed to acquire new language remain intact throughout the lifespan and that it is actually perception, not production mechanisms, which cause phonetic errors in adults (Ioup, 2008). Flege's argument against a set cutoff for the optimal age of acquisition is that no specific age has shown a particular drop off in linguistic aptitude when tested empirically.

One shortcoming of the critical period hypothesis is that it is not predictive of all L2 learners - specifically, the identification of a critical period does not explain why some post-critical L2 learners fare much better than others at mastering L2 phonemic systems, nor does it explain why not all children achieve native-like pronunciation if exposed to an L2 during the pre-critical stage. In Flege and Hillenbrand (1984), the researchers support the validity of the proposed "critical period" but refute the rigidity of the hypothesis based on a belief that, given environmental conditions comparable to those encountered during L1 acquisition (particularly a full-emersion environment in which the speaker has an urgent need to be understood), the L2 speaker can continuously improve upon the native-like pronunciation of target phonemes without ever reaching an impetus. Ioup (2008) identifies this continual L1 input (that is, an environment where the L2 is not the dominant daily language) as a contributive factor in the failure of "early" bilinguals to achieve native-like L2 pronunciation.

Linguistic environments such as this may explain the results of Flege's studies of Korean-English and Italian-English bilinguals, which led him to the conclusion that the $\mathrm{CPH}$ cannot be the only predictive factor which is sustained empirically in large data samples because a sizeable number of "pre-critical" bilinguals continue to carry a foreign 
accent. At any rate, it should be remembered that Flege's SLM and Kuhl's NLM model are attempts to complement, and not invalidate, the $\mathrm{CPH}$.

Most researchers agree that, even in L2 acquisition, there exists a biological window before adolescence during which time the acquisition of a second language produces more phonetically accurate target sounds. It is the purpose of the current study to determine whether early learners, some of whom are English-dominant whereas others continue to receive large amounts of L1 input at home, are more capable of perceiving and producing reduced vowels in intersentential environments than those who learned English after the critical period.

\subsection{Flege's "Speech L earning M odel"}

One of the most commonly referenced theoretical models of cross-linguistic perception is Flege's (1995a) Speech Learning Model (SLM hereout). Concerned with linguistic acquisition and development over the course of L2 acquisition (measured in years, not months), the SLM navigates the pitfalls of L1 interference and incorrect perceptual judgments on the part of the L2 speaker. At the heart of the SLM is the concept that, though not without certain difficulties, the linguistic faculties involved in language acquisition remain present throughout a person's lifespan - namely, there is no physiological reason why adults cannot acquire a language as rapidly, and with as much flexibility, as children do (see Ioup, 2008).

Flege's model primarily addresses issues involving phonetic production, and later on perception, of L2 phonemes. In addition to outlining the framework by which a speaker's L1 is perceptually categorized in the brain, the SLM also grapples with issues of variable success rates in producing native-like L2 phonemes. In his theories regarding 
perception, Flege acknowledges the difficulties in perceiving new L2 sounds after the solidification of an L1 phonemic system. These difficulties arise because the incoming L2 phonemes are not mapped into a vacuum, but rather must be included, and distinguished, from a fully-formed L1 phonological system which crowds out sounds whose production difference is more subtle (i.e., "dental t" [ ] versus "alveolar t" [t]). Flege also concedes that, while adults retain the capacity to map and store new phonemes just as children do, the process is inhibited by these four factors: cross-linguistic similarity, age of arrival, frequency of L1 usage, and the storage of L1 and L2 categories in a community space, as mentioned above (Escudero, 2007).

One point which seems counterintuitive to the casual observer's perception of language is that it seems easier for L2 learners to acquire sounds they perceive as "foreign" over sounds they perceive to be "similar." Flege postulates that the phonemes acquired in L1 and L2 share a mutual phonemic inventory space from which target sounds may be retrieved. Therefore, if a sound is perceived as existing in a previously occupied section of a speaker's phonemic inventory, the new target sound is perceived as a positional allophone and the L1 phonological system subsequently filters out information which identifies the target phoneme as a unique L2 sound to be acquired in a process known as "equivalence classification." (see Yavas, 2011). It follows that the greater difference between sounds relates directly to perception of the new phoneme due to the fact that phonetically distinct sounds will be perceived more readily than sounds which share multiple phonetic properties. Flege et al. (1981, 1984, 1987, 1997, 2005) write extensively on the effects of new and similar phones as evidence for a system of equivalence classification. 
The SLM model maintains that adult learners encounter difficulty processing or categorizing L2 phonemes if information highlighting the contrastive properties in L1 and L2 sounds is susceptible to filtering processes, or can be a "nonlearned sound" due to perceived similarity. It follows then that sounds which differ markedly from the L1 with regard to place and manner features will form new phonological categories in the brain and be more easily identifiable, and therefore, recoverable.

It is an aim of the SLM is to present a comprehensive explanation of the strategies L2 speakers employ when presented with phonemes not included in the L1 inventory. Therefore, the levels of L2 phonemic identification can be trisected into three categories: "identical," "similar," and "new." Identical sounds pose no problem for the L2 learner, who simply transfers L1 feature information onto the L2 phoneme. "Similar" sounds often lead the L2 speaker to retrieve features reserved for L1 phonemes in an effort to produce sounds which are "close enough" to the target phoneme through a process of assimilation, while allowing for a minimal expansion of the phonemic inventory. "New" sounds contribute to the formation of previously nonexistent phonological categories, meaning the speaker is conscious that a new sound, complete with a unique feature set, has been acquired which is identified as "foreign" when compared to the L1 phonemic inventory.

Escudero (2007) defines sound perception, as realized in the SLM, as follows: "...the discerning of the phonetic features or properties in the signal that make it possible to identify the appropriate 'positional-defined allophones' or 'phonetic categories' of the language" (122). Flege's aim, in the development of SLM, is to determine whether certain L2 segments are either unlearnable, given a speaker's L1 phonetic inventory, or 
learnable only by children as the CPH would suggest. The tendency of SLM is to refute any target sound as completely unlearnable, though perceptual difficulties may take years of exposure to overcome. Bohn and Munro (2007) pinpoint a fundamental postulate of SLM as the assertion that "the mechanisms and processes used learning the L1 sound system remain intact over the lifespan" (5).

The distinction between certain features of separate languages, such as VOT in English versus Spanish, becomes more complicated in early bilinguals. Researchers believe that, rather than being in possession of two separate phonologies, early bilinguals often assign a compromise value to similar sounds in an effort to appease the requirements of both languages (Flege, 1991). The production of these voiceless stops in early bilinguals is able to satisfy the voicing requirement for intelligibility in English, yet consistently measures as far shorter duration in aspiration than one finds in monolingual English speakers. An explanation offered by the SLM is that when an L2 phoneme is not perceived as being a separate sound from the L1 inventory, presumably because of the similarity with a preexisting segment, the two segments will merge to create one whose values approximate the difference in the target sounds.

One final aspect of the SLM which is crucial to understanding the development of L2 phonologies deals with the acquisition of new phonemes when an introduced sound is perceived as separate from the L1 phonological system. Flege (1995a) hypothesizes that when a new segment is acquired in the L2 inventory, some speakers may undergo an unconscious process of dissimilation, in order to further distance the new sound from preexisting sounds in the oral cavity in order to maximize phonemic contrast. This dissimilation process may result in an overdifferentiation between L1 and L2 phonemes, 
which the SLM believes will be gradually corrected, or refined, throughout the course of the language learning process. For this reason, later additions to the SLM advocate for viewing dissimilation between L1 and L2 segments as a continuum rather than the originally proposed tripartite structure from the 1984-1993 model.

\section{$1.4 \mathrm{~K}$ uhl's "Native L anguage Magnet Model"}

The Native Language Magnet Model of language acquisition conceives of phoneme acquisition as a complex set of phonological abstractions, a markedly different approach from the phonetic compromises and target undershoots previously discussed. According to Kuhl (2000), infants learn the perceptual mappings of their ambient language. Her Native Language Magnet Model (NLM hereafter) highlights the emergence of neural maps in order to perceive speech signals. First the infant is exposed to all of the L1 phonemes through constant contact with caregivers, which the infant perceives as "signals." As these signals are eventually decoded, the representations become stored in the memory (known as a "mapping process") where they form the basis of linguistic production (Escudero, 2007). These mapping processes are specific for each individual language, an impediment to linguists attempting to uncover universal mapping systems which could apply to all languages. Kuhl (2000) further proposes that infants' perception of sounds becomes categorical in nature due to statistical processing, which results in a patterning of the acoustic parameters of speech sounds somewhere between the ages of six and twelve months.

The mapping of acoustical parameters into a classification of "sounds" can be extremely problematic for second language learners who are attempting to map the new language onto the appropriate phonetic categories. This is a result of the fact that these 
idealized representations have become anchored in the brain, causing a perceptual interference when non-native phonemic categories are presented (Ioup, 2008). Furthermore, the existence of this filter for the purpose of capturing sounds, which contains a relatively complete "native language" by the age of twelve months, makes learning an another language as an adult extremely difficult. As Flege suggested, learning "similar" sounds also becomes an issue because the prototype of a given phoneme acts as a magnet - thus forcing the hearer to perceive the new phoneme as the prototype (Ioup, 2008). The Native Language Magnet Model seems to refute certain tenets of the $\mathrm{CPH}$ on the basis that the onset of puberty is not responsible for neurological changes, but rather it is implementation of initial mental mappings onto the neurological pathways which create barriers to accepting foreign phonemes later on in life. Escudero (2007) suggests the major underdevelopment of NLM exists in its failure to provide a physical account of how the perceptual mappings for two languages are separated in the brain, nor does the NLM explain how the activation of overlapping regions in the brain is achieved in young children. The NLM does not account for language acquisition successes outside of L1 acquisition in infancy, though it does explain how the process of filtering out non-native sounds begins.

Kuhl's hypothesis would seem to exclude the fact that children who learn another language after one year of age still acquire the L2 phonemic system much easier than adults. Kuhl suggests in response that early in life it is possible to acquire multiple neurological mappings because interference effects (from the L1 representations) are considered to be minimal. For adults, she hypothesizes, it is impossible to have overlapping regions of the brain when processing two languages, though this is not 
necessarily the case when bilingualism is acquired early in life. This would seem to serve more as a modification of the $\mathrm{CPH}$ than as a purely non-linguistic explanation of language acquisition.

\subsection{Contemporary I ssues in R educed V owel A nalysis}

Having established the theoretical frameworks through which the data in the current study will be analyzed, it is worthwhile to highlight several of the major instrumental studies which have previously been conducted on bilingual populations. Numerous longitudinal studies (Flege and Bohn, 1989; Flege, Munro, and Fox, 1994; Flege, Bohn, and Jang, 1997; Flege and MacKay, 2004, et al.) have been conducted regarding L2 phonological achievement across different age (and language) groups. Thompson (1991) collected speech samples of Russian immigrants, both as free speech and reading samples, and rated the productions for accentedness (see Patkowski, 1994). Among a wide variety of independent variables Thompson tested, AoA was the most reliable predictor of a perceivable accent. It is important to mention, however, that participants who arrived in the United States before the end of the critical period were judged to have a lesser accent than those who came as adults, which is not synonymous with the claim that the child learners were devoid of accent.

“Accentedness" tests a monolingual population's reactions to L2 production in non-native speakers. However, testing the role of perception in the L2 speaker must be conducted through a separate course of study. One of the most common methods used to test L2 speaker perception is by testing consonants or vowels which do not contrast in the speaker's L1 inventory. Flege and MacKay (2004) perform exactly this experiment when testing the ability of Italian L2 English learners' abilities to discriminate between / $\mathbf{D}$ / - 


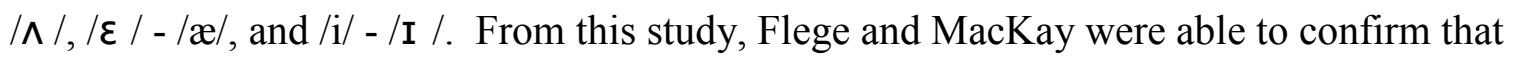
two conditions were necessary for native-like vowel discrimination: the participant must have acquired English before the onset of the critical period and also must not be operating in an L1-dominant environment. That is, participants who categorized themselves as high-use Italian speakers scored significantly lower on the discrimination test than participants who, for all intents and purposes, are L2 dominant.

In determining perceptual abilities across Spanish-English bilinguals, Flege, Munro, and Fox (1994) found that abilities to differentiate between English vowels is not so much the product of length of exposure to the English vowel inventory as the ability to perceive dissimilarity is dependent upon the amount of space which lies between vowels in question. These findings contain interesting implications for the current study on vowel reduction because it poses the question: will Spanish-English bilinguals be more capable of perceiving reduced vowels in instances where the full vowel (which underwent reduction) extends further to the periphery? Will L2 speakers be able to hear the difference in their interphonological full vowel substitutions, or will perception biases filter out the acoustic properties of SAE's schwa substitutions? Another study of interest to the present group of participants is Flege and Bohn's (1989) investigation of L1 Spanish speakers' pronunciation of morphophonological alternations in English words (i.e. "able" vs. "ability") - however, the size of the instrument in this study would have to be greatly increased in order to access generalizations about Spanish-English bilinguals as a population.

The role of L2 perception in making discrimination judgments in English vowels has been thoroughly established across a wide variety of L1 groups. The current seeks to 
contribute to the ongoing study of L2 phonological production by examining vowel reduction in Spanish-English bilinguals across eight distinct phonological environments. These environments have been identified as reliable environments to test measurable characteristics of target reduced vowels. Analysis of F1 and F2 values in the target schwas, as well as duration, will uncover patterns regarding the production of reduced vowels in SAE in both early and late Spanish-English bilinguals, the results of which will contribute to a better understanding of the perception and production errors L2 SAE speakers make when faced with a language which employs an unusually large vowel inventory and unfamiliar prosodic features that must be overcome if the speaker is to develop the stress-timed syllable structure which characterizes American English. 


\section{CHAPTER 2. Research Design and Methodology}

The previous chapter identified a significant gap in the research pertaining to reduced vowel productions in L2 SAE speakers. Being home to a large and diverse population of bilinguals who operate in both languages during their daily lives, Miami lends an opportunity to research schwa production in people whose L1 (or one of their L1s) does not allow for reduced vowel production. The present study draws from bilinguals who, because of prolonged exposure to SAE, are capable of producing schwas, as well as participants who have varying levels of success in producing reduced vowels. This second group, termed "late bilinguals," may experience success reducing vowels in certain prosodic context while failing in other structures.

In order to perform a quantitative analysis of the patterns in reduced vowel production across three populations, it is necessary to amass a sizeable corpus of recorded utterances containing the target phone [ə]. This research design requires a large collection of data samples from a demographically varied group of participants in order to minimize the influence of any particular dialect or speaking pattern over the general results. The research design further emphasizes the need to test participants in a variety of phonologically-conditioned environments. The incorporation of multiple environments ensures that emergent patterns are actually the result of variation in the production of reduced vowels and not of any one prosodic feature. The purpose of this wide-scope investigation is twofold: to predict spectral and temporal patterns of reduced vowel production among monolingual, early bilingual, and late bilingual populations, and to analyze the implications of these productions as they relate to studies of L2 perception. 


\subsection{Participants}

Statistical analyses of contemporary studies which were comparable in design indicated that sixty-six participants, subdivided into equal groups of monolinguals, early bilinguals, and late bilinguals, would be ideal for ensuring statistical significance of the data. The decision was made to increase the number of participants to seventy-five in order to further justify the results of the study as comparable to the general population. For the purposes of this study, monolinguals were classified as native speakers of English who did not acquire a second language prior to the "critical period" (Birdsong, 1999). The acquisition of another language, such as learning French or Japanese in secondary school, was not cause for disqualification for the study, provided the monolingual was self-classified as living in a home where only L1 is spoken, received her formal education in the L1, and that she speaks only L1 in the majority of social situations (Appendix A). Early bilinguals are identified for the purposes of this study as speakers whose native language is not American English and where L2 American English was acquired before the age of ten. There is considerable disagreement regarding the boundaries of the “critical period" (see Long, 1990; Birdsong, 1999). While Long maintains that L2 acquisition must begin before the age of six to acquire native-like pronunciation, other researchers have set the boundaries at a more reasonable "before the onset of puberty" criteria. For the purposes of the current study, the age of ten years was used as a cutoff for early bilinguals in order to assure maximal distinction between early and late L2 speakers, while providing a comfortable cushion between the maximal age of these participants and adolescence. Given the location of the experiment, metropolitan Miami, it was found that the linguistic situation for the majority of early bilingual speakers 
consisted of L1 Spanish acquisition in the home, followed by L2 American English being acquired by the speakers sometime between pre-school and kindergarten. The mean age for early bilinguals' age of L2 acquisition was 4.76 years of age, which is consistent with the criteria for classifying a speaker as a "pre-critical bilingual."

Late bilingual participants are defined in the current study as those speakers who began to seriously acquire American English at age fifteen or beyond. This categorization provides a five year separation in age of acquisition (AoA) from the early bilinguals, thus providing adequate separation between the early and late participant groups. These participants were more difficult to collect due to the prerequisite that participants read English sentences which were primed to change every three seconds. Eliciting a conversational-rate of speaking through the rapid- reading of sentences required L2 speakers who were both fluent and highly literate.

The majority of these twenty-five participants were of Cuban descent, with the next highest groups being Venezuelan, Puerto Rican, and Spanish, respectively (Appendix B, C). The average age of L2 acquisition for this group was 22.68 years. As a consequence of the late average age of acquiring L2 American English, it follows that the late bilingual group was significantly older as a whole than the early bilingual group, many of whom were university students. The age difference is consistent, however, with the range of monolingual participants, whose ages spanned from ages eighteen to sixty, thus reconciling both bilingual test groups to the same demographic parameters set forth by the control group. 


\subsection{Materials - I nstrument I}

It was determined that participants would read English sentences from a computer screen in order to assess characteristics of specified unstressed syllables in the target words. The first experiment measures spectral and temporal qualities of schwa across three environments which are phonologically conditioned for schwa. In constructing the instrument, target words were placed as either the first word in the sentence, or second following only a single determiner or modifier (Appendix D). The placement was a calculated effort to avoid the effects of haphazard word placement or the influence of suprasegmental features. Sentences underwent interjudge reliability to ensure consistency in the stress and intonation patterns of each construction. To elicit these utterances, sentences were constructed which contained the following environments:

\subsubsection{Plural Morpheme}

In this section the second word of each sentence was constructed with the syllable-final phonological environment: "sibilant + plural morpheme $\{-\partial z\}$ ", as in "watches" [w $\square \square \mathrm{oz}]$ and "sashes" [sæ $\square$ zz]. All of the target words present the reduced vowel in a post-tonic environment, where the schwa is nestled between two sibilant consonants.

Ex: "Three judges took a vote."

"These sashes tie in the front"

\subsubsection{Possessive Mor pheme}

Target words containing the combination of "reduced vowel + possessive morpheme" were further restricted to the construction "sibilant + possessive morpheme 
$\{\partial z\}$ as in the words "Marsha's" [m $\square \square \square \partial z]$ and "niece's" [nisəz]. The use of proper names created sentences in which it was sometimes necessary to place the target word first in the sentence. With common nouns, such as "niece's" and "judge's," the ordering of "determiner/modifier + target word" was retained in order to assure maximum similarity with the sentences containing plural morpheme targets.

Ex: "My niece's team won the game." "Lisa's twin looks just like her."

\subsubsection{R educed V owels in W ord-Final Position}

This section of the instrument tests words where the final syllable is unstressed and is, therefore, mandatorily reduced as in "sofa" [sofə] and "ninja" [nI ndzə]. In this section of the instrument words containing reduced vowels in word-final position were placed in medial position within the sentence to avoid further lengthening of the target

sound. Furthermore, all target sentences were constructed to follow the target schwa with coronal $/ \mathrm{t} /$ to control for variables in sound placement

$$
\begin{aligned}
& \text { Ex: "A trip to Russia takes money" } \\
& \text { "The tuba takes strength to play." }
\end{aligned}
$$

This section of the instrument was further divided into three phonetic categories for the purposes of testing if the vowel qualities and the duration of word-final schwa are affected by the preceding consonant. The consonants in question were divided into distinct categories which represent three major places of articulation in American English, namely: labial [f,b], coronal $\left[\mathrm{d} 3 \int\right]$, and dorsal $[\mathrm{k}, \mathrm{g}]$. While this sampling is 
not inclusive of all the consonants in the aforementioned categories, these six phonemes occur in markedly different areas of the oral cavity and can be seen as an adequate sampling of the American English consonant inventory. Participants were presented with two sentences each, comparatively similar in length and suprasegmental features, containing the "target 'point of articulation' consonant + reduced vowel" environment.

Ex: "A ninja tiptoes in the dark."

"Wear a toga to the party"

"A sofa takes two people to lift it."

\subsection{Instr ument II}

The second experiment is a quantitative analysis of the production of wordinternal reduced vowels in environments characterized as "deletable" schwa or "nondeletable" schwa ("DS" or "NS" here out). Deletable schwas are vowels which have undergone multiple layers of reduction to become mid-central lax articulations due to their position adjacent to a stressed syllable ("pretonic" or "post-tonic" throughout). Following this process of reduction, the schwa may undergo optional deletion which collapses the vowel nucleus, thereby reducing the number of syllables in the word by one.

$$
\begin{gathered}
\text { Ex: }[\text { fæm li }] \rightarrow[\text { fæmoli }] \rightarrow[\text { fæmli }] \\
{[\text { pr } \square \text { bobli }] \rightarrow[\text { pr } \square \text { bəbli }] \rightarrow[\text { pr } \square \text { bli }]}
\end{gathered}
$$

In NS environments, the vowel may also be reduced to schwa in pretonic or post-tonic position. However two criteria prevent the reduced vowel from undergoing deletion: the vowel does not precede a second reduced vowel in the following syllable (as in 
"testimony"), or the deletion of the reduced vowel would place primary and secondary stress adjacent to one another in the word, which is in contradiction with patterns of stress in American English.

$$
\begin{aligned}
& \text { Ex: }[\mathrm{t} \quad \text { stI móni }] \rightarrow[\mathrm{t} \quad \text { stəmóni }] \rightarrow *[\mathrm{t} \quad \text { stmóni }]
\end{aligned}
$$

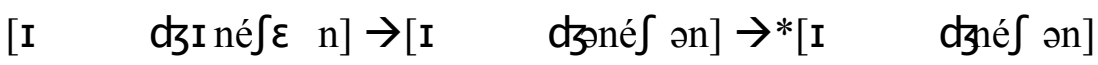

Semantically-related words were chosen from both DS and NS categories to measure duration of the target schwa. Vowel quality measurements were also taken for the target words in order to properly identify vowel substitutions where did not occur.

\subsection{1. "Deletable Schwa" Instr ument}

Six sentences were created using target words containing medial reduced vowels that are phonologically conditioned to undergo optional deletion, as in "general"

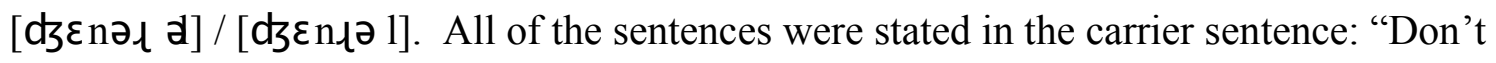
say , say " to ensure that no prosodic features interfered with vowel production.

\section{Ex: "Don’t say principal, say first." \\ "Don’t say probably, say maybe."}

Four control sentences were randomly interspersed throughout this section of the instrument; however, they were not measured for any aspect of vowel production. These control sentences did not follow the same intonation patterns as the target sentences. After a pilot trial containing only the "Don't say __, say ___ "sentences, it was 
determined that control sentences would be necessary to vary the tempo of the readings and to hold the attention of the participants.

\subsection{2. "Non-Deletable Schwa" Instrument}

In accordance with the same pattern as the DS instrument, the words chosen for this section contain reduced vowels that do not lend themselves to deletion. These nondeletable reduced vowels occur in words which contain both primary and secondary stress. Though a weak vowel, the schwas in these target words must maintain the syllable nucleus to prevent adjacent primary and secondary stress syllables - the positioning of such syllables is unfavorable in American English. The NS words chosen for this section of the experiment are also semantically related to the DS category to assure maximum phonetic similarity between the target words. Examples included

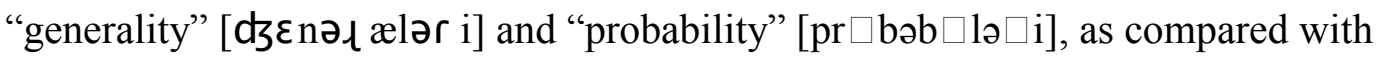
"general" and "probably" outlined above. These sentences follow the same pattern "Don't say ___ say ___ " to free the target words of the effects of unwanted interference (Appendix D).

\section{Ex: "Don't say principality, say town." \\ "Don't say testimony, say account."}

In keeping with the DS portion of the instrument, this NS section also contains four control sentences interspersed throughout the instrument for the purpose of creating variety in rhythm and preventing monotonous pronunciations by the speaker. 


\subsection{Procedure}

Participants were situated alone in a quiet conference room with a personal computer to read the instrument. The sentences were automatically timed to move forward at three second intervals, where speakers were not required to actively progress the instrument. It was the case that several participants were unable to complete entire sentences at this speed; however, the data collection process was not jeopardized by the speed of the instrument because of the early placement of target words in the sentences. The rapid pacing of this instrument was deemed necessary to maintain the "normal speech" tempo which is required for conditioned schwa deletion.

Utterances were recorded on a Sony ICD digital recorder and converted to MP3 files, which were then analyzed for temporal and spectral qualities using PRAAT speech analyzing software. The F1 and F2 values for each vowel were determined by taking the mean value of the center of each target nucleus. Measurements were interjudged for reliabity with an agreed upon accuracy rating of $94 \%$ given the parameters of not more than $50 \mathrm{~Hz}$ difference between $\mathrm{F} 1$ and $\mathrm{F} 2$ measurements, or not more than $.05 \mathrm{~ms}$ difference in duration. These measurements also contained an intrajudge reliability of $95.5 \%$.

In analyzing the data, the average F1 (vowel height) values of the sibilant + plural morpheme, sibilant + possessive morpheme, and word-final schwa environments were ranked within each participant group to determine within-group tendencies. The same step was repeated for the F2 values within each group, and the F2-F1 values (indicating the relative position of a sound within the oral cavity) were also compared within each 
group. Reduced vowels were isolated from the target word and measured for duration, as well as F1 and F2 formants to identify vowel height and backness.

\subsection{Explanation of the procedure}

The optimal environment for eliciting reductions in vowels is fast conversation between people who share a relationship (Patterson, Locasto, and Connine 2003). However there are severe limitations concerning a researcher's ability to elicit specific, semantically-related constructions. Coaxing bilinguals, particularly late bilinguals, to produce these target words in the context of extemporaneous speech would not yield consistent results. The present study acknowledges that obtaining speech productions through the act of reading alters the rhythm and tempo of syllable production. Piske and colleagues (2001) found that read speech has been judged as possessing a "stronger foreign accent" when rated by monolingual speakers, perhaps due to the failure of many bilinguals to receive formal education in L2 literacy. However, the productions elicited by reading sentences fulfill the immediate purpose of providing comparative analyses of the various qualities of reduced vowels within and between monolingual, early bilingual, and late bilingual groups.

Presently, the accentedness of the production of reduced vowels elicited by reading, as opposed to natural conversation, is less the focus of the current study than is the variation which occurs between productions based on morphological differences. This instrument allows for the comparison of all the aforementioned features by group, and produces data which allows for a ranking of these features in a hierarchical manner (with regard to duration, vowel height/backness). It is believed that the results obtained 
from this technique accurately portray the similarities and differences in the way each participant group perceives and produces reduced vowels in distinct environments.

\subsection{Methods of A nalysis}

The first portion of the experiment, measuring duration and F1, F2 values of schwa in the sibilant + plural morpheme $\{-\partial z\}$ as in "sashes," sibilant + possessive morpheme $\{-\partial z\}$ as in "Lisa's," and schwa in word-final position as in "Russia," compares results within-groups to determine which groups were able to differentiate spectral and temporal characteristics in seemingly homophonous environments. The statistical test chosen to determine the significance of vowel qualities/quantities within groups was a one-way ANOVA repeated measures. An ANOVA test is designed to evaluate the equality the means, with the ultimate aim of disproving the null hypothesis (that the results between groups should show insignificant statistical variation).

Parameters for significance were set at .05 , where means averaging less than this number were deemed to be significantly different. F1, F2, and F2-F1 values (indicative of overall positioning of the sound in the oral cavity) were assessed within-groups in this manner.

Regarding between-group analyses, a one way ANOVA test was applied to compare the mean values of F1, F2, and F2-F1 in each phonological environment against the same environment in the remaining populations. The purpose of this test is to compare three or more independent groups where each group contains the same number of participants and they are being tested on a variety of variables, all of which must ultimately be judged independently. In certain cases, paired-sample T-tests were later applied to two of the three populations for direct comparison of variables deemed to have significant difference by the wide-scope ANOVA test. The purpose of including T-tests, 
which produce redundant values, is to directly, and more simply, compare values of one variable between two populations in order to make a clear and readable generalization of the data. These t-tests alone would not be sufficient for data analysis, as the margin for error greatly increases as multiple t-tests are run, as compared to the efficiency of a oneway ANOVA repeated measures test, which also provides a usable effect size for each variable in question.

The first portion of experiment also tested vowel duration using the plural, possessive, and word-final environments. In keeping with the uniformity of statistical testing, a one-way ANOVA repeated measures test was chosen to synthesize the results. The "within-subjects effects" test also allows for data to be collected from the same participants and subsequently measured across a variety of environments, with individual differences between participants minimized because of the repetition of the measurements. The ANOVA test was also used to compare the average duration between populations. To determine the significance of variation in the mean lengths of duration, Fisher's Least Significant Difference (LSD) post hoc test was administered at .05 level, denoting a $95 \%$ confidence interval.

While late bilinguals were originally excluded from cross-population comparison in the duration portion of the experiment, due to perception and production errors which posited peripheral vowels in lieu of schwas, the decision was later made to incorporate the data through paired-sample T-tests directly comparing late bilinguals with early bilinguals, and late bilinguals against monolinguals. It is important to recall that the data presented in Chapter 4 regarding this section will likely compare unreduced vowels with reductions performed by monolinguals and early bilinguals - however; the results of late 
bilingual quantitative productions in any form shed light on the perception and production capabilities of this particular population.

From the first portion of the experiment a further subsection of the data was analyzed whereby word-final schwas were compared for both duration and vowel qualities based on the places of articulation each reduced vowel follows. Post-labial, post-coronal, and post-dorsal schwas were analyzed for length using a one-way ANOVA repeated measures test on the three environments to determine whether variation in the either spectral qualities or durations reached statistical significance. As a complement to the ANOVA test, Fisher's LSD post hoc test was also run with a standard confidence level of .05 , or $95 \%$ percent confidence interval.

The second experiment collected data from the bipartite categories of "deletable" (DS) and "non-deletable" (NS) words ${ }^{3}$ for the purpose of analyzing duration patterns between groupings. Within this instrument, all of the target words consist of semantically-related items in which one word allows for optional deletion of a syllable and the other word does not.

$$
\begin{gathered}
\text { Ex: "testament" / "testimony" } \\
\text { "general" / "generality" } \\
\text { "probably" / "probability" }
\end{gathered}
$$

The data in this section were analyzed using paired-sample t-tests to determine if significant differences arise in the duration of these reduced vowels in each set of words.

\footnotetext{
${ }^{3}$ For a complete description of the phonological environments conditioning "deletable" and "non-deletable" environments, see section 3.3.
} 
The test is run only within-subjects for the purpose of determining which groups, if any, place special emphasis on durational differences between the pairs. It is not necessary to compare the durations between-groups; rather, it is the intention of this portion of the experiment to determine whether early and late bilingual groups perceive and reproduce the patterning established by monolinguals in differentiating between "deletable" schwa and "nondeletable" schwa targets.

\section{CHAPTER 3. Results and Discussion}

Results of the experiment are presented below, given the data analysis procedures outlined in section 2.6. Section 3.1 highlights the important findings regarding spectral and temporal qualities of schwas occurring in the plural and possessive morphemes, as well as in word-final position. These results are compared both as within-group analyses and across groups to determine patterns of schwa pronunciation among all three participant groups. Section 3.2 provides a comparison of the mean durations of deletable and nondeletable schwas (DS and NS hereout) within groups and across groups to determine if the difference reaches statistical significance. Section 3.2 further deconstructs the data into semantically-related pairs in order to provide a clearer explanation of the strategies employed by different speaker groups when pronouncing medial schwa in a variety of morphological contexts. Section 3.3 provides useful commentary regarding the collection and synthesis of data in the current experiment. 


\section{1 Experiment 1}

\subsubsection{Experiment 1(a) V owel Qualities Comparison}

In comparing the duration of reduced vowels situated within plural morphemes, possessive morphemes, and in word-final environments, a clear hierarchical pattern emerges with regard to vowel height across morphological categories. Within each population the F1 formant (height) is highest in word-final position, lower in the possessive morpheme, and lowest when it occurs within the plural morpheme. Because of the inverse relationship which exists between vowel height and F1 formants, the results confirm that word-final schwas are lower vowels, plural schwas are produced higher in the mouth, and possessive schwas fall somewhere in between. Figures 3.1.1a-c provide an illustration of the variation in F1 vowel qualities production between the three environments:

Table 3.1.a. Pairwise comparison of F1 values across monolinguals

\begin{tabular}{|ll|r|r|r|}
\hline & & $\begin{array}{c}\text { Mean } \\
\text { Difference }\end{array}$ & Std. Error & Sig. \\
\hline Fl Environment & Fl Environment & $-16.160^{*}$ & 3.712 & .000 \\
& $\begin{array}{l}\text { Possessive } \\
\text { Word-final }\end{array}$ & $-75.160^{*}$ & 7.662 & .000 \\
\hline Possessive & Plural & $16.160^{*}$ & 3.712 & .000 \\
& Word-final & $-59.000^{*}$ & 6.509 & .000 \\
\hline Word-final & Plural & $75.160^{*}$ & 7.662 & .000 \\
& Possessive & $59.000^{*}$ & 6.509 & .000 \\
\hline
\end{tabular}

*. The mean difference is significant at the .05 level.

Table 3.1 a displays a pairwise-comparison chart whereby each category (plural, possessive, or word-final) is compared against exactly one other category in order to determine if the differences in F1 values are statistically significant. The highlighted 
regions demonstrate with confidence that there is statistically significant difference in the vowel heights of each category in this population. For monolinguals, the estimated marginal mean value for schwa in plural morphemes was $414 \mathrm{~Hz}$, which is considerably lower than canonical schwa values. Schwas in the plural morpheme average $431 \mathrm{~Hz}$, which is lower still than the mean of $490 \mathrm{~Hz}$ for schwa in word-final position. Values for the monolingual control group may be summarized as follows (where the $>$ sign indicates a higher F1 value):

\section{Word-final $>$ Possessive Morpheme $>$ Plural Morpheme}

Table 3.1.b-c presents comparative analyses of the pair-wise contrast between F1 values in all three environments for both the early and late bilingual groups.

Table 3.1.b. Pairwise comparison of F1 values across early bilinguals

\begin{tabular}{|ll|c|c|c|}
\hline \multirow{2}{*}{ Fl Environment } & Mean Difference & Std. Error & Sig. \\
\hline Plural & Possessive & -21.560 & 4.527 & .000 \\
& Word-final & -73.560 & 7.570 & .000 \\
& & & & \\
\hline Possessive & Plural & 21.560 & 4.527 & .000 \\
& Word-final & -51.960 & $\mathbf{5 . 8 1 2}$ & .000 \\
& & & & .000 \\
\hline \multirow{2}{*}{ Word-final } & Plural & 73.520 & $\mathbf{7 . 5 7 0}$ & .000 \\
& Word-final & $\mathbf{5 1 . 9 6 0}$ & $\mathbf{5 . 8 1 2}$ & \\
& & & & \\
\hline
\end{tabular}

*. The mean difference is significant at the .05 level.

The above comparison for early bilinguals indicates a pattern which is very similar to the monolingual group. All F1 values between the plural, possessive, and word-final morpheme are significantly different from one another. Interestingly, early bilinguals display a mean F1 value of $414 \mathrm{~Hz}$ in the plural morpheme, which is identical to the 
average value for monolinguals. The early bilingual participants displayed a remarkable similarity to the vowel heights posted by monolinguals, as the possessive height of 436 $\mathrm{Hz}$ (compared to 431 in monolinguals) and $488 \mathrm{~Hz}$ in word-final position (490 in the control group) show almost no variation in pronunciation. The situation diverges a bit with regard to late bilinguals, as figure 3.1.c demonstrates:

Table 3.1.c. Pairwise comparison of F1 values across late bilinguals

\begin{tabular}{|lc|c|c|c|}
\hline \multirow{2}{*}{ Fl Environment } & Mean Difference & Std. Error & Sig. \\
\hline \multirow{2}{*}{ Plural } & Possessive & 24.400 & 7.665 & .004 \\
& Word-final & 97.520 & 15.327 & .000 \\
\hline \multirow{2}{*}{ Possessive } & Plural & 24.400 & 7.665 & .004 \\
& Word-final & -73.120 & 15.656 & .000 \\
\hline \multirow{2}{*}{ Word-final } & Plural & 97.520 & 15.327 & .000 \\
& Possessive & 73.120 & 15.656 & .000 \\
\hline
\end{tabular}

* The mean difference is significant at the .05 level.

While all three categories easily reach statistical significance among the late bilingual group, it is immediately apparent that the amount of variation in the F1 production of late bilinguals is much higher than for the early bilinguals and monolinguals $(\mathrm{p}=.004$ compared with $\mathrm{p}<.001)$. The standard error is also much higher, indicating that an individual's production of any given target schwa may vary significantly from the mean value assigned to each section. The mean value for schwa in the plural morpheme was $480 \mathrm{~Hz}$ for late bilinguals, a value which is closer to canonical [ə] than the [ $\dot{\mathfrak{t}}]$ sound approximated by monolinguals and early bilinguals. Nevertheless, late bilinguals continue to follow the hierarchical pattern for F1 values: word-final > possessive $>$ plural as outlined by monolingual speakers. While possessive schwa averages $504 \mathrm{~Hz}$, the 
word-final mean of $577 \mathrm{~Hz}$ indicates a blurred area of perception between [ə] and Spanish [a], as some participants produced values in the $600+\mathrm{Hz}$ range to produce such a mean. Figure 3.1.d plots the average F1 values for the plural morpheme, possessive morpheme, and word-finally across all three language groups.

Figure 3.1.a Across-groups comparison of $F 1$ values in plural, possessive, and word-final environments

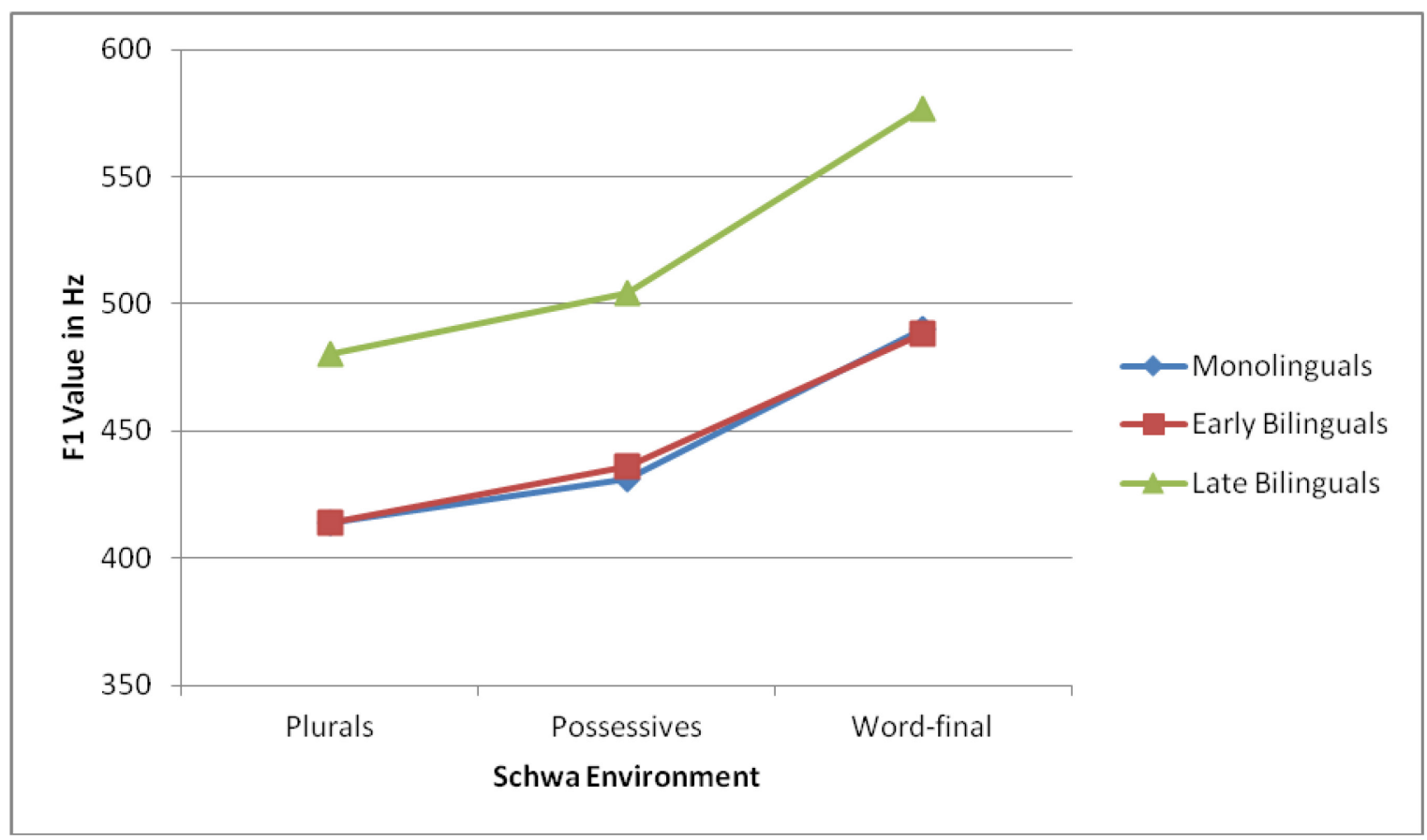

In Figure 3.1.a, a fascinating pattern emerges with regard to target vowel height. It appears that early bilinguals are able to very closely approximate the vowel height of native speakers - a feat which is all the more impressive given the sociolinguistic context of the experiment. Miami is a city populated by bilinguals across every generation. Therefore, the logical assumption is that Miami natives, even those who learned English at a young age, would have received bilingual, not monolingual native speaker, phonological input in L2 learning. Yet, despite this less-than-ideal situation for L2 
phonological acquisition, early bilinguals have perceived and produced reduced vowels whose central height values are remarkably similar to those of native speakers.

The second vowel quality in question, described succinctly as the position of a vowel on the "front/back" continuum in the oral cavity (identified by the phonological feature [+back]), was measured by analyzing F2 formants. In spectral analysis, high F2 values coincide with front vowels, whereas low F2 vowels indicate that the vowel was articulated farther back in the mouth. In vowel reduction, it is assumed that F2 will carry a midrange value, which is consistent with the idea of vowel quality neutralization. In the current study, F2 measurements in monolinguals carry an inverse relationship to F1 formants in that the highest F2 formants are found in plural morphemes, with comparatively lower F2 formants in possessive morphemes, followed by the lowest F2 formants in word-final position as demonstrated by the hierarchy:

\section{Plural Morpheme $>$ Possessive Morpheme $>$ Word-Final Position}

This hierarchy was maintained by across all three populations, though several interesting patterns were detected through statistical analysis. While monolinguals met the expectation of statistically significant differentiation in the backness of vowels between plural, possessive, and word-final environments, the F-value of this group was much higher than in the other two populations. These high F-values indicate a wider range of variability within the population with regard to vowel production. Specifically, the F-value implies that the mean may not be indicative of the broad spectrum of F2 values produced by monolingual speakers. 
Early bilinguals, on the other hand, showed surface differentiation between all three phonological environments; however, when standard deviation is considered, the significant difference between plural and possessive categories is nullified $(p=.055)$. Though nearly reaching significance, this p-value indicates that the production of reduced vowels in plural and possessive morphemes is in reality quite close. The following pattern is indicative of F2 hierarchical values in early bilinguals:

\section{Plural Morpheme $\approx$ Possessive Morpheme $>$ Word-Final Position}

Late bilinguals pattern more like monolinguals in that there are significant differences between the F2 values of schwa in the plural morpheme, possessive morpheme, and word-finally. The major difference for this population is the rate of intragroup variation for $F 2$ values where $F(2,48)=29.659$. This signifies a wide range of variability within the late bilingual group. Essentially, this wide scope of variability reveals that, though the means are comparable to monolingual values in each category, there is much less uniformity regarding the relative backness of schwas in late bilinguals. Nevertheless, the hierarchy of mean F2 values for late bilinguals is identical, through this particular measure, to that of monolinguals:

\section{Plural Morpheme $>$ Possessive Morpheme $>$ Word-Final Position}

The final set of variables compared in Experiment 1(a) was the overall mean measurement of F2-F1 formants, which plots vowel height against backness to identify the quadrant of the oral cavity where a particular vowel production occurs. The location in the mouth is then compared across groups to determine if the target vowels are being 
produced in the same region of the mouth. Average F2-F1 values were compared between populations using a one-way ANOVA repeated measures test to determine if significant difference exists between vowels produced between the plural morpheme, possessive morpheme, and word-final environments Table 3.1.a displays a crosslinguistic comparison by phonological environment:

Table 3.1.d. Mean values of F2-F1 for monolingual, early bilingual, and late bilingual populations

On first inspection it is apparent in table 3.1.d that monolingual, early bilingual, and late bilingual populations follow the same pattern with regard to hierarchical rankings of F2F1 values. In each participant group, the following trend is observed:

\section{Plural Morpheme F2-F1 > Possessive Morpheme F2-F1 >}

\section{F2-F1 in Word-Final Position}

It is noteworthy that monolinguals display slightly lower F2-F1 values in articulating reduced vowels in both the plural and possessive morphemes, which fails to corroborate Flemming's $(2007,2009)$ assessment that monolingual speakers articulate higher $[\dot{\mathfrak{t}}]$ vowels in these positions. These numbers notwithstanding, it is possible, given the high levels of variation (F-value), that many monolingual speakers do utilize this allophone and that their productions have been overshadowed by the mean.

The pattern is a bit different however, with regard to F2-F1 values of schwa in word-final position. Here monolinguals display a slightly higher mean F2-F1 $(1250 \mathrm{~Hz})$ as compared with both bilingual groups $(\mathrm{EB}=1163, \mathrm{LB}=1185$.) These results likely 
signify that monolinguals do not utilize as low of a vowel (F1) in word-final position as do the bilingual groups. Perhaps the phonetic similarity between schwa and Spanish [a] causes target undershoot, which is highlighted in this particular environment. The data presented in 3.1.d, however, fail to support a significant distinction between linguistic groups ( $\mathrm{p}=734, .772, .099$ respectively). These numbers present a picture of relative similarity in across-groups testing, which suggests that the most relevant factors involving spectral quality variation occur within each individual group, and how each group categorizes F1 and F2 values for a particular phonological environment is where differentiation most likely occurs.

\subsubsection{Experiment 1(b) R educed vowel duration: A cross-group comparison}

This section provides an across-group analysis of reduced vowel duration where schwa occurs in either the plural morpheme, possessive morpheme, or word-finally. It is the intention of this section of analysis to examine whether bilinguals who learned English in childhood are able to make the same subtle alternations in vowel length that monolinguals demonstrate, and to further see if the differences in production are significant. Figures 3.1.e-g display a pairwise comparison of vowel duration within all three groups to assess how each language group articulates vowel duration across multiple environments. 
Table 3.1.e. Pairwise Comparisons of average duration in monolingual speakers

\begin{tabular}{|ll|c|c|c|}
\hline Vowel Duration in Monolinguals & Mean Difference & Std Error & Sig \\
\hline Plural & Possessive & & \\
& Word-Final & .008 & .002 & .002 \\
& Plural & -.008 & .004 & .032 \\
\hline Possessive & Word-Final & -.008 & .002 & .002 \\
& Plural & -.017 & .003 & .000 \\
\hline \multirow{2}{*}{ Word-Final } & Possessive & .008 & .004 & .032 \\
& & .017 & .003 & .000 \\
\hline
\end{tabular}

*. The mean difference is significant at the .05 level.

The measure of difference in duration between the plural, possessive, and wordfinal environments indicates that all three durations are significantly different from one another in monolinguals. Schwa in the possessive morpheme carries the shortest average duration $($ mean $=.067 \mathrm{~ms})$, followed by schwa in the plural morpheme $($ mean $=.075 \mathrm{~ms})$. Predictably, the longest of the reduced vowels is word-final schwa (mean $=.083 \mathrm{~ms})$. A Greenhouse-Geisser test further confirms significance where $\mathrm{f}(2,48)=14.452$ and $\mathrm{p}$ $<.001$. Thus, the following pattern serves as a control for the bilingual test groups:

\section{Word-Final Duration $>$ Plural Duration $>$ Possessive Duration}

Early bilinguals display a remarkably similar durational hierarchy, with possessive-morpheme schwas characterized as shortest in duration (mean $=.068 \mathrm{~ms}$ ), followed by reduced vowels in the plural morpheme (mean $=.076 \mathrm{~ms})$. Word-final schwa contains the longest duration $($ mean $=.083 \mathrm{~ms})$. The near-identical measurements in duration are quite remarkable, yet it must be considered that aggregate data such as a group mean does not provide a comprehensive portrayal of the variation in duration 
spoken by early bilinguals and monolinguals due to dialectal differences, as well as aforementioned social factors. These results give indication that early bilinguals are quite sensitive to the patterns of reduced vowel duration produced by native speakers. Tests of within-subjects effects are very similar to those of the monolinguals in that $f(2,48)=$ 14.564 and $\mathrm{p}<.001$.

Table 3.1.f Pairwise comparison of reduced vowel durations in early bilinguals

\begin{tabular}{|ll|c|c|c|}
\hline Vowel duration in early bilinguals & Mean Difference & Std Error & Sig \\
\hline Plural & Possessive & & & \\
& Word-Final & .008 & .002 & .002 \\
& Plural & -.007 & .003 & .056 \\
\hline Possessive & Word-Final & -.008 & .002 & .002 \\
& Plural & -.015 & .003 & .000 \\
\hline \multirow{2}{*}{ Word-Final } & Possessive & .007 & .003 & .056 \\
& & .015 & .003 & .000 \\
\hline
\end{tabular}

However, it is interesting to note that while the differences in duration reach statistical significance between all three groups in the monolinguals, the differences between schwa in the plural morpheme and word-final schwa not reach statistical significance (sig: .056) though the actual means were very close in number (significance in this study occurs at the .05 level). According to the analysis, temporal distinctions in early bilinguals should be arranged as follows:

\section{Word-final Duration $\approx$ Plural Duration $>$ Possessive Duration}

Late bilinguals present yet a third pattern of distribution for reduced vowel length as evidenced by table 3.1.g. Within the late bilingual group, the difference in duration 
between plural and possessive schwas is not statistically significant. Both plural and possessive reduced vowels are statistically different from those produced word- finally.

Table 3.1.g. Pairwise comparison of the duration of reduced vowels in late bilinguals

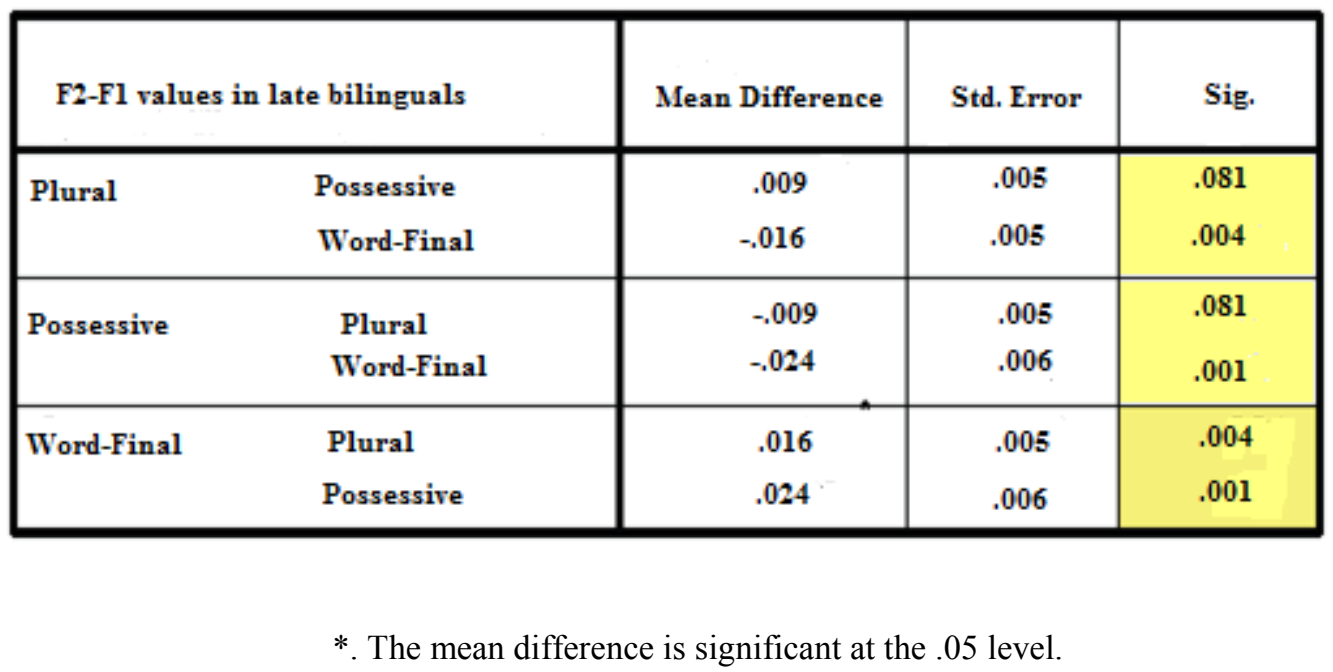

Having failed to reach statistical significance between the duration of vowels in plural and possessive environments, it is possible to encapsulate gradation between the three environments as follows:

\section{Word-Final Duration $>$ Plural Duration $\approx$ Possessive Duration}

A comparison of each category across groups, using a one-way ANOVA repeated measures test, found no significant differences in the values of duration between populations. It should be noted that this test produced relatively high standard deviations $($ std dev. $=.015-.030)$, suggesting that a lack of statistical significance does not imply that there are no obvious differences in measurement between groups. What these tests more concretely reveal is that the central issue in reduced vowel durations, for the designated environments, emphasizes the three contrasting ways in which vowel durations are 
ranked - a pattern which varied three times in as many populations. An inability to perceive the slight alternations native speakers make in reduced vowel production may well contribute to the failure of certain bilinguals to master larger prosodic features of American English.

These alternations lead to a final question regarding vowel quality production in these three environments: Do reduced vowels in word-final position behave differently based on the phonological features of the consonant that they follow?

\subsubsection{E ffects of preceding consonants on vowel duration in word-final position}

The vowels in focus were also examined for vowel qualities and duration into the following categories: post-labial vowels, post-coronal vowels, and post-dorsal vowels. The aim of this experiment is to determine whether the CV\# environment is affected by the place of articulation which characterizes the syllable onset. Measurements were taken from all three populations and compared within groups to determine if similar duration patterns would be found in all three populations. Standard deviations for each measurement range between .015 and .02 , respectively. In the following figures 3.1.b-d, post-labial (as in "tuba), post-coronal (as in "Russia"), and post-dorsal (as in "toga") vowel durations are presented for each participant group. 
Figure 3.1.b. Mean duration for schwa in CV\# position in monolinguals

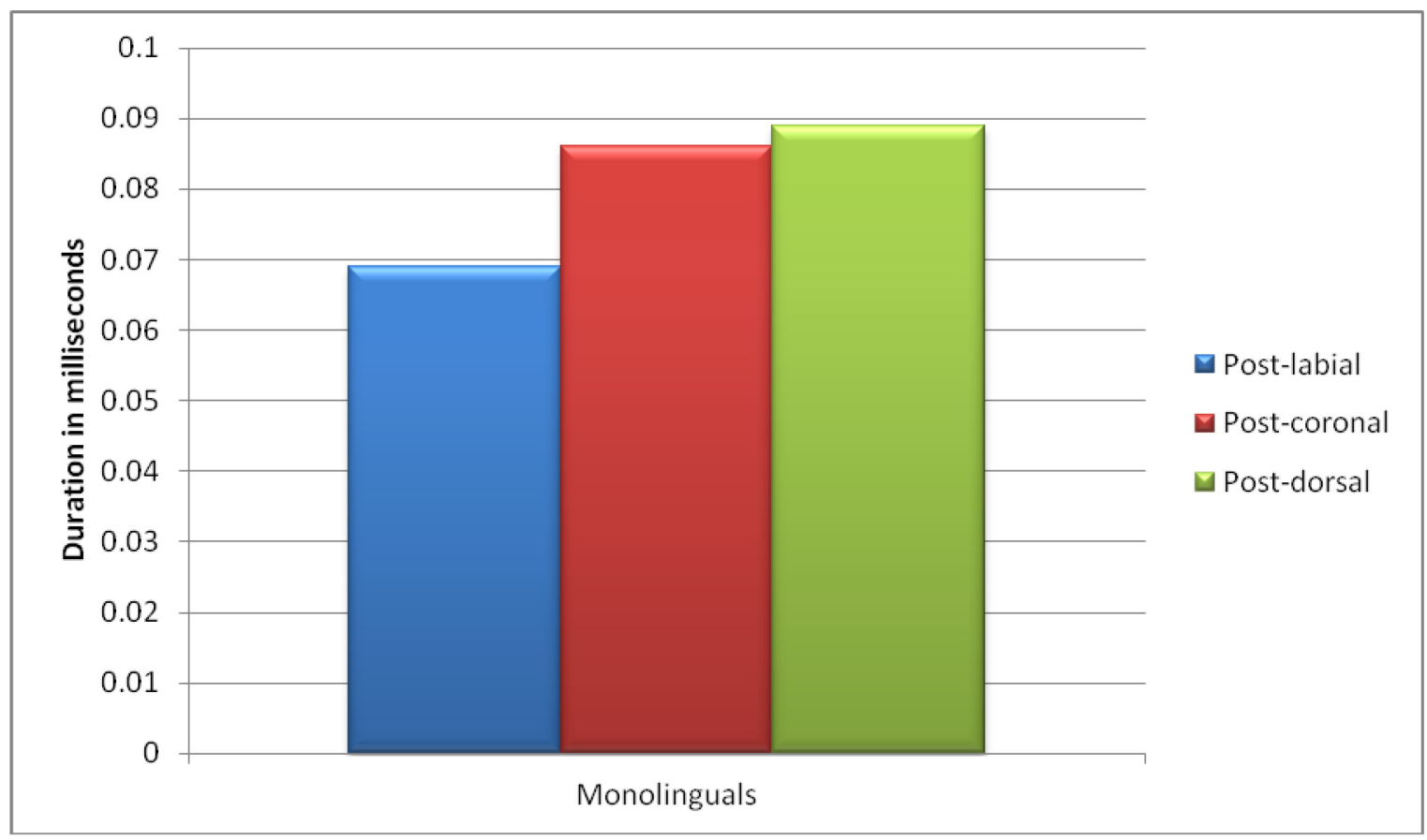

While post-labial vowels are significantly different from post-coronal $($ sig. $=.001)$ and post-dorsal $($ sig. $=.002)$, there is no statistical significance which differentiates postcoronal from post-dorsal ( $\mathrm{sig} .=.391$, where the mean difference is significant at the .05 level).

As shown in figure 3.1.i, the same overall pattern displayed in figure 3.1.h holds true for early bilinguals. Post-dorsal durations are longer than post-coronal, which in turn are longer than schwas in post-labial position. Despite the apparent similarity to the trends displayed in monolinguals, the standard deviations begin increasing in early bilinguals, a trend which will be magnified in late bilinguals (std. dev. $=.015-.026$ for each of the three places of articulation). This implies less uniformity in production, though the overall pattern is quite similar to monolinguals. 
Figure 3.1.c Mean duration for schwa in $\mathrm{CV} \#$ position in early bilinguals

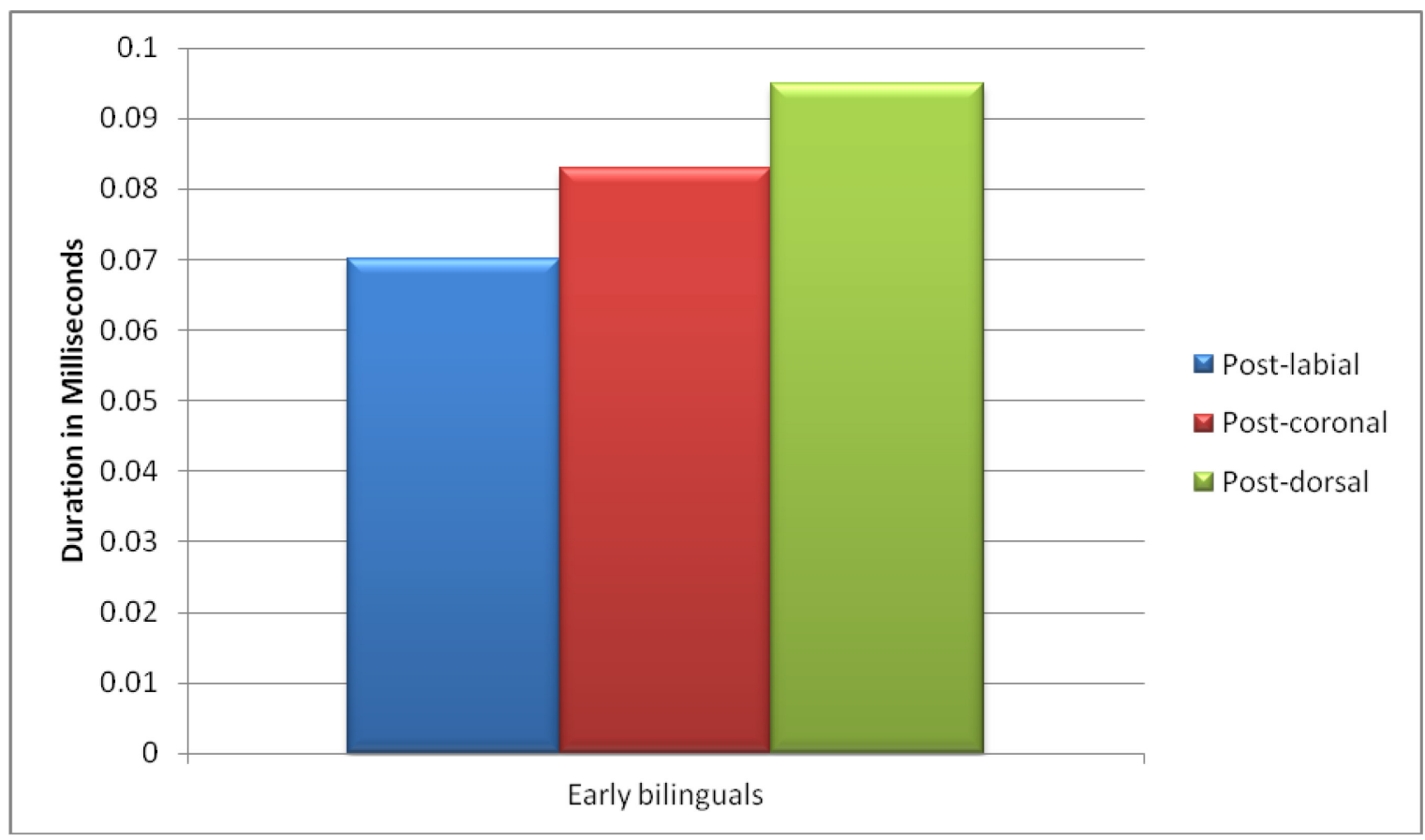

Though the increase in standard deviation tempers any predictions to be made regarding word-final schwa duration in early bilinguals, it is interesting to note that early bilinguals are the only participant group to reach statistical significance in comparing all three phonological environments: post-labial, post-coronal, and post-dorsal. The least significant difference in these environments for early bilinguals occurred between postcoronal and post-dorsal environments $(\mathrm{p}=.026)$, though the difference is overwhelmingly more significant than the same environments in monolinguals $(p=.391)$. The late bilingual data presented in figure 3.1.j patterns similarly to the monolinguals and early bilinguals; however, as figure $3.1 . \mathrm{k}$ will illustrate, these are surface similarities which do not carry the same implications for late bilingual vowel duration. 
Figure 3.1.d Mean duration for schwa in CV\# position in late bilinguals

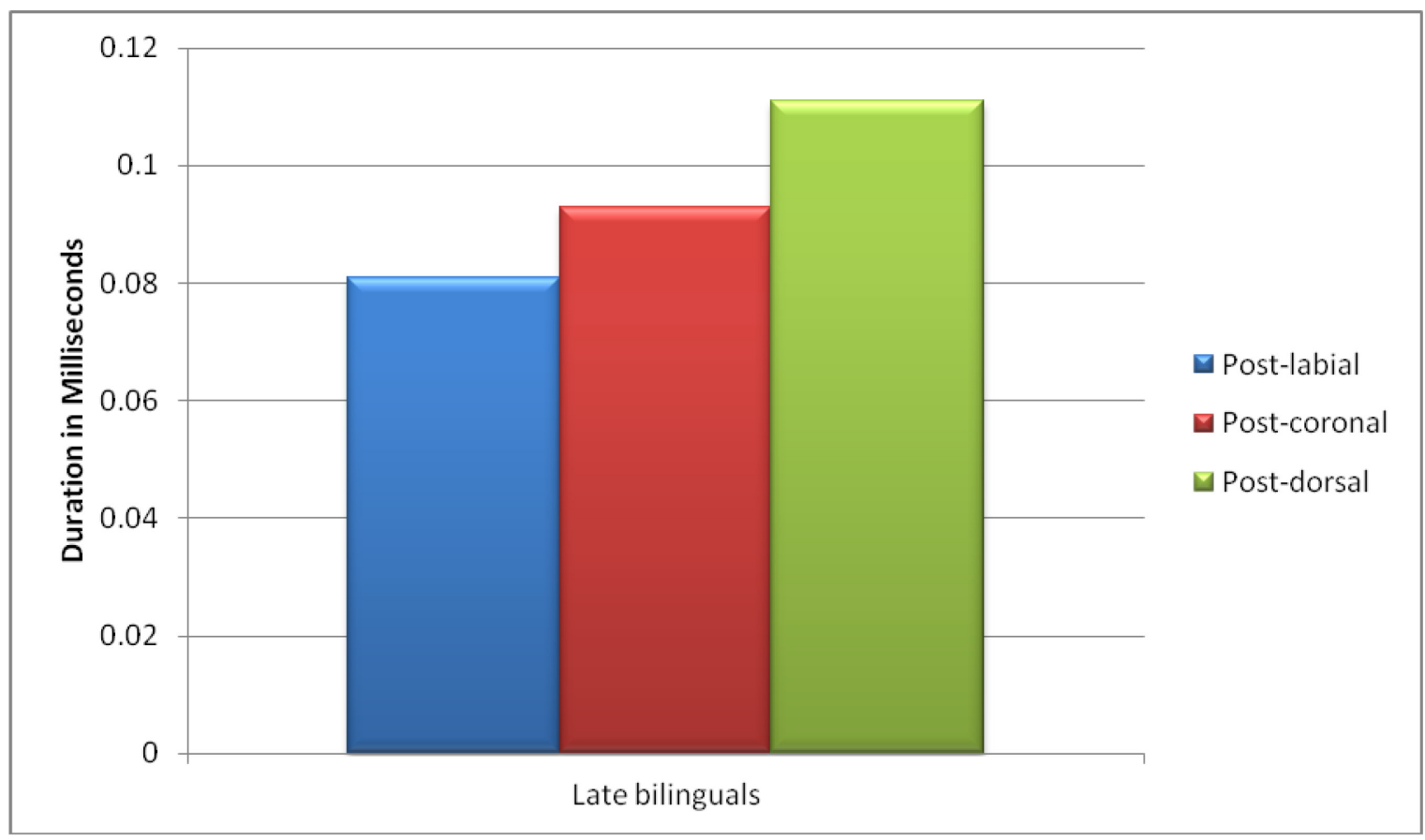

While late bilinguals continue the pattern 'post-labial < post-coronal < post-dorsal,' the durations are longer in each category than either the monolingual or early bilingual groups. Because of the unusually high standard deviations in the measurements of late bilinguals (std. dev. $=.022-.044)$ none of the differences in duration between phonological categories reaches statistical significance for late bilinguals. The high standard deviations are indicative of widely variant patterns with regard to reduced vowel duration, which implies that the pattern may not be as uniform as a simple comparison of the means would suggest. Figure 3.1.k highlights the contrast in significance for late bilinguals, so that a clearer picture may immerge. 
Table 3.1.h Across-category comparison of word-final vowels in late bilinguals

\begin{tabular}{|c|c|c|c|}
\hline $\begin{array}{l}\text { Duration of schwa in word- } \\
\text { final position in late } \\
\text { bilinguals }\end{array}$ & Mean Difference & Std. Error & Sig. \\
\hline $\begin{array}{ll}\text { post-labial } & \text { post-dorsal } \\
& \text { post-coronal }\end{array}$ & $\begin{array}{l}-.030 \\
-.011\end{array}$ & $\begin{array}{l}.015 \\
.012\end{array}$ & $\begin{array}{r}.066 \\
.393\end{array}$ \\
\hline $\begin{array}{ll}\text { post-dorsal } & \text { post-labial } \\
& \text { post-coronal }\end{array}$ & $\begin{array}{l}.030 \\
.019\end{array}$ & $\begin{array}{l}.015 \\
.012\end{array}$ & $\begin{array}{r}.066 \\
.141\end{array}$ \\
\hline $\begin{array}{ll}\text { post-coronal } & \text { post-labial } \\
& \text { post-dorsal }\end{array}$ & $\begin{array}{r}.011 \\
-.019\end{array}$ & $\begin{array}{l}.012 \\
.012\end{array}$ & $\begin{array}{l}.393 \\
.141\end{array}$ \\
\hline
\end{tabular}

*. The mean difference is significant at the .05 level.

The above chart attests, unquestionably, to the lack of statistical significance between phonological environments when produced by late bilinguals. In the next section, the results of vowel quality measurements of schwa in CV\# position, following post-labial, post-coronal, and post-dorsal consonants is synthesized.

3.1.4. E ffects of segmental features on the vowel qualities of reduced vowels in wordfinal position

The purpose of this portion of the experiment is to determine whether the spectral qualities of word-final schwa move to assimilate to the location of the preceding consonant. To make this determination, the F1 and F2-F1 values for each category were compared within each linguistic group. After these measurements had been obtained, the mean data from each $\mathrm{C} \_$_ environment were compared across populations to provide a comparative analysis of vowel quality production between groups. Figures 3.1.e-g provide a comparative analysis of the mean F1 vowel qualities across all populations. For a complete record of average values and standard deviations, see Appendix D. 
Figure 3.1.e Across-groups comparison of F1 values in post-labial CV\# environments ${ }^{4}$

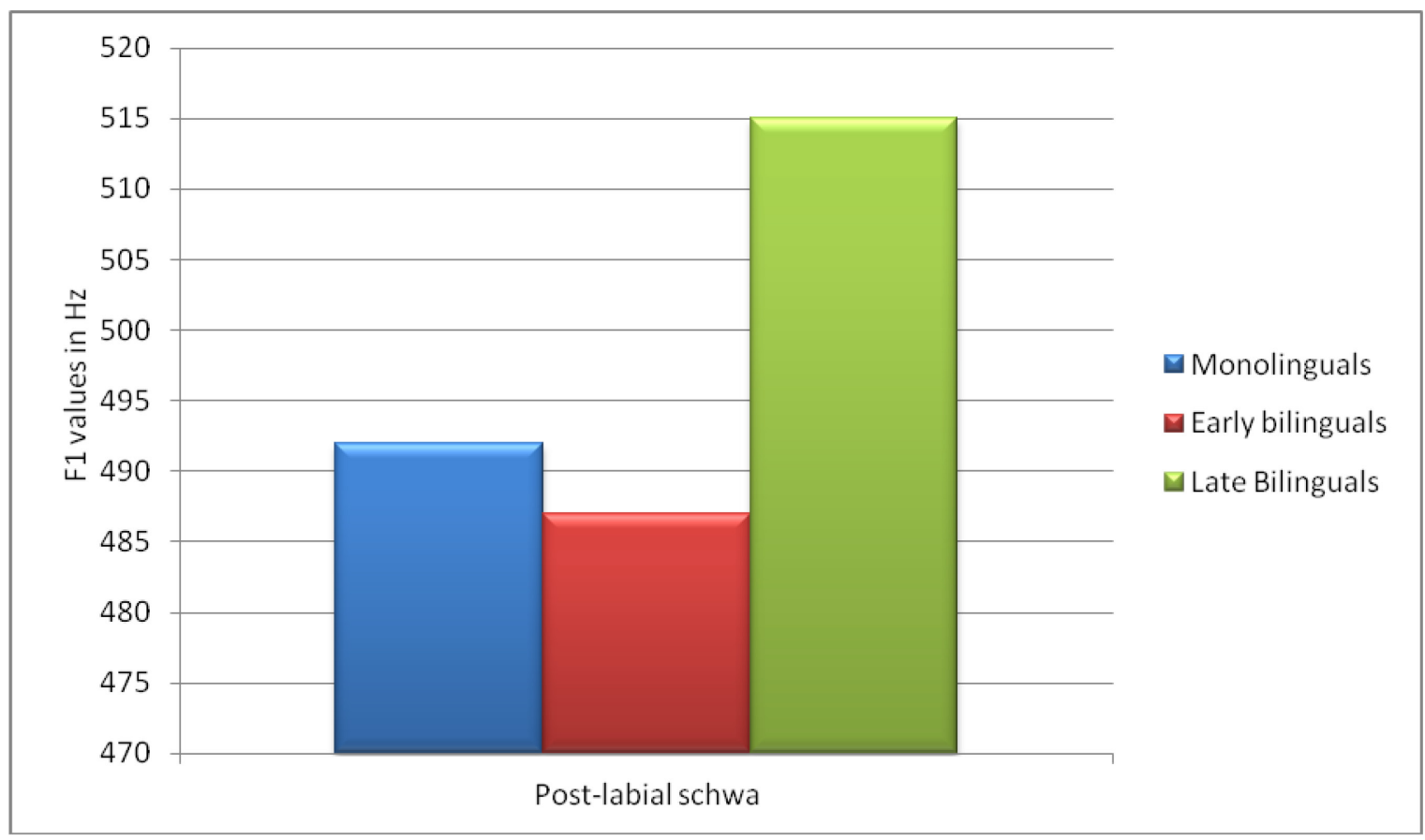

In section 3.1.1 all participant groups were found to have the lowest F1 values in wordfinal position. As figure 3.1.e displays, the mean value for F1 in post-labial \# environments is $492 \mathrm{~Hz}$, a relatively canonical value for schwa in monolingual American English speakers. While late bilinguals had the highest F1 value in post-labial position, this is to be expected due to the fact that late bilinguals had the highest F1 values in all categories tested. Figures 3.1.f-g below present across-group comparisons of postcoronal and post-dorsal environments.

\footnotetext{
${ }^{4}$ Higher F1 values indicate that the target vowel is produced lower in the oral cavity.
} 
Figure 3.1.f Across-groups comparison of $\mathrm{F} 1$ values in post-coronal $\mathrm{CV} \#$ environments ${ }^{5}$

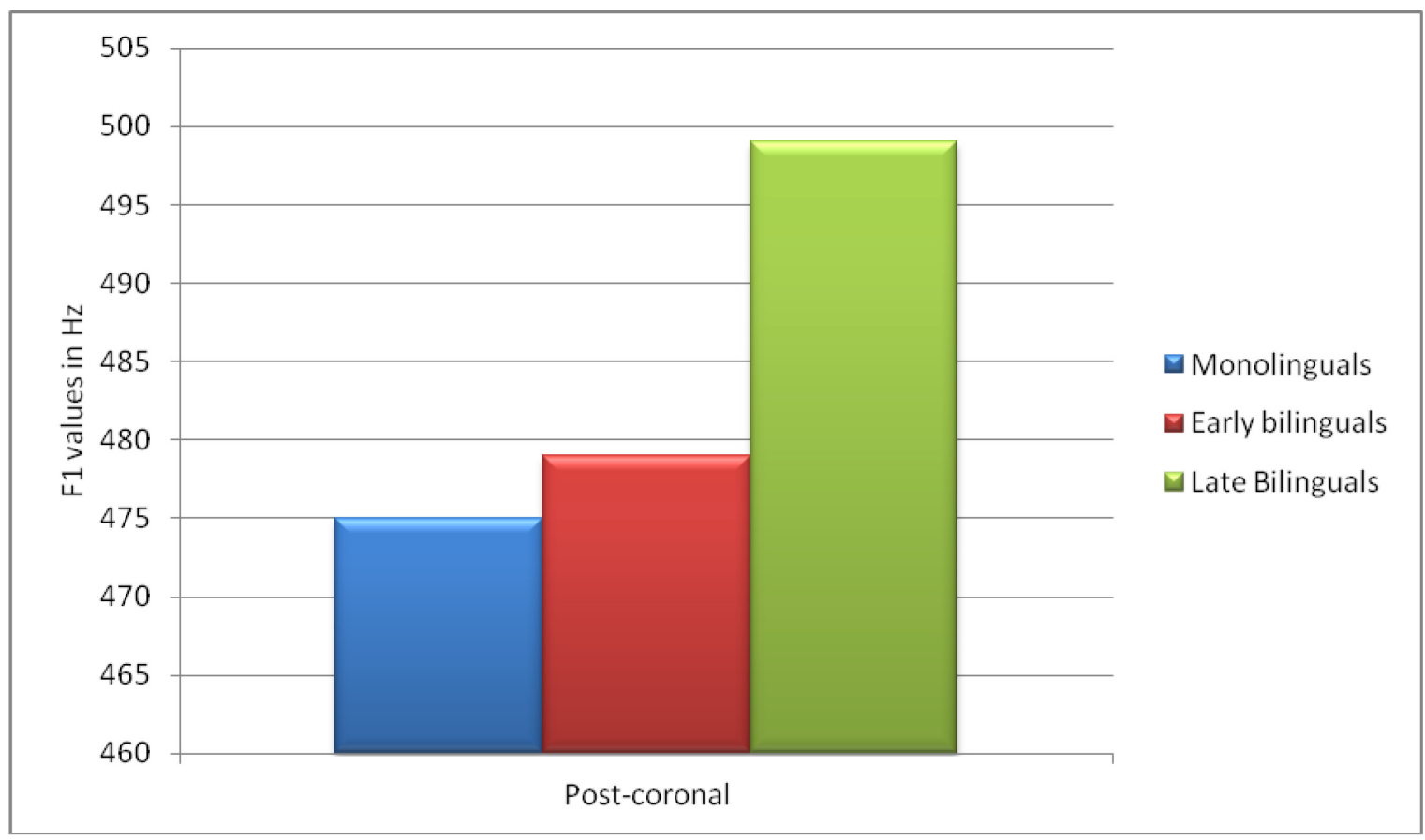

${ }^{5} \mathrm{~F} 1$ values carry an inverse relationship to the position of the vowel in the oral cavity. A high F1 value indicates the production of a low vowel and vice versa. 
Figure 3.1.g Across-groups comparison of F1 values in post-dorsal CV\# environments

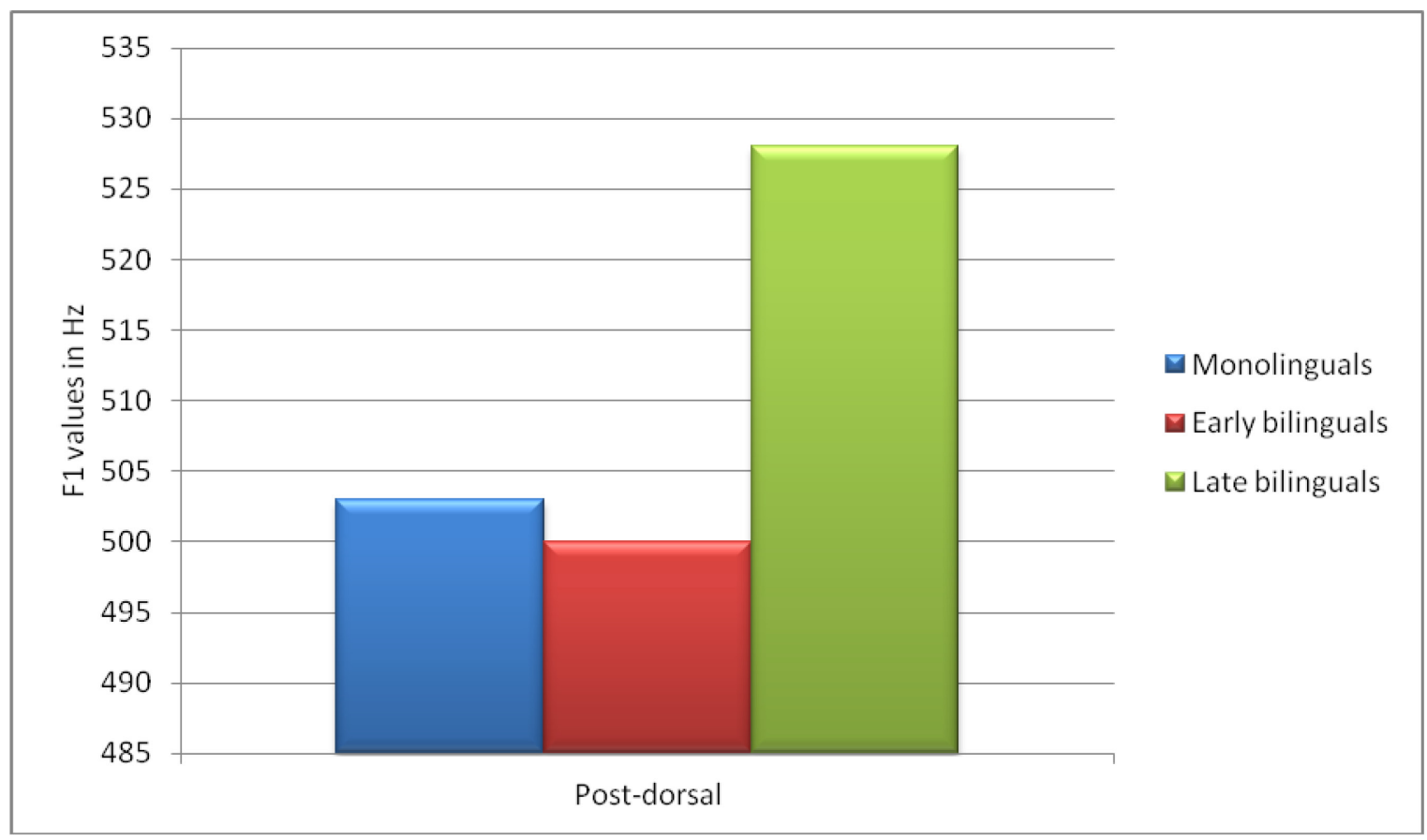

The above figures present a clear picture of the comparative values of group's mean within an isolated environment. A further application of multivariate statistical tests uncovers three contrastive patterns within the linguistic groups. In monolinguals, the F1 values, from least to greatest, may be interpreted as:

\section{Post-dorsal $>$ Post-labial $>$ Post-coronal ${ }^{6}$}

In contrast, early bilinguals, who to this point have patterned monolinguals in many aspects, display the pattern:

\section{Post-dorsal $>$ Post-coronal $>$ Post-labial}

6 " >” sign indicates a higher F1 value 
Late bilinguals display an average pattern equal to that of monolinguals in the established hierarchy of:

\section{Post-dorsal $>$ Post-labial $>$ Post-coronal}

A within-groups comparison, where all three places of articulation were compared in one group only, returned several intriguing items. While monolinguals show no significant differences between post-labial and post-dorsal articulations $(\mathrm{p}=.198)$. Furthermore, the difference between post-labial and post-coronal environments is barely significant $(\mathrm{p}=.048)$. Indeed, it is only the difference between post-coronal and postdorsal articulations that can be confidently stated to have predictable differentiation $(\mathrm{p}=$ .000) When taken together, these numbers indicate that the difference in F1 vowel qualities across these environments is not so significant in monolinguals as to rule out coincidence. A similar phenomenon occurs in late bilinguals who show significance only between post-dorsal and post-coronal articulations, and this difference was marginally significant $(\mathrm{p}=.043)$. Conversely, all three places of articulation were significantly different for early bilinguals. F1 values are useful points for spectral analysis because they provide useful clues about which vowel[s] the speaker is targeting. In languages, such as Spanish, where the phonemic inventory contains widely-spaced vowels, obtaining an F1 vowel in isolation provides useful cues about the speaker's perception of an L2 vowel. However, it is necessary to measure multiple spectral values for a vowel in order to determine its overall location within the oral cavity. Therefore, it is obligatory to also obtain F2-F1 values for schwa in post-labial, post-coronal, and post-dorsal environments 
if a determination is to be made concerning the effects of target overshoot/undershoot on the existence of a perceived foreign accent.

For the second section of this experiment, average F2-F1 values (indicative of the overall positioning in the mouth based on the formula "backness-height") were analyzed to determine if the place of articulation [post-labial, post-coronal, or post-dorsal] significantly affects vowel height or relative backness in the mouth. Figure 3.1.h provides an across-groups comparison of these means for each participant group. ${ }^{7}$

Figure 3.1.h Descriptive Statistics of F2-F1 positioning across groups

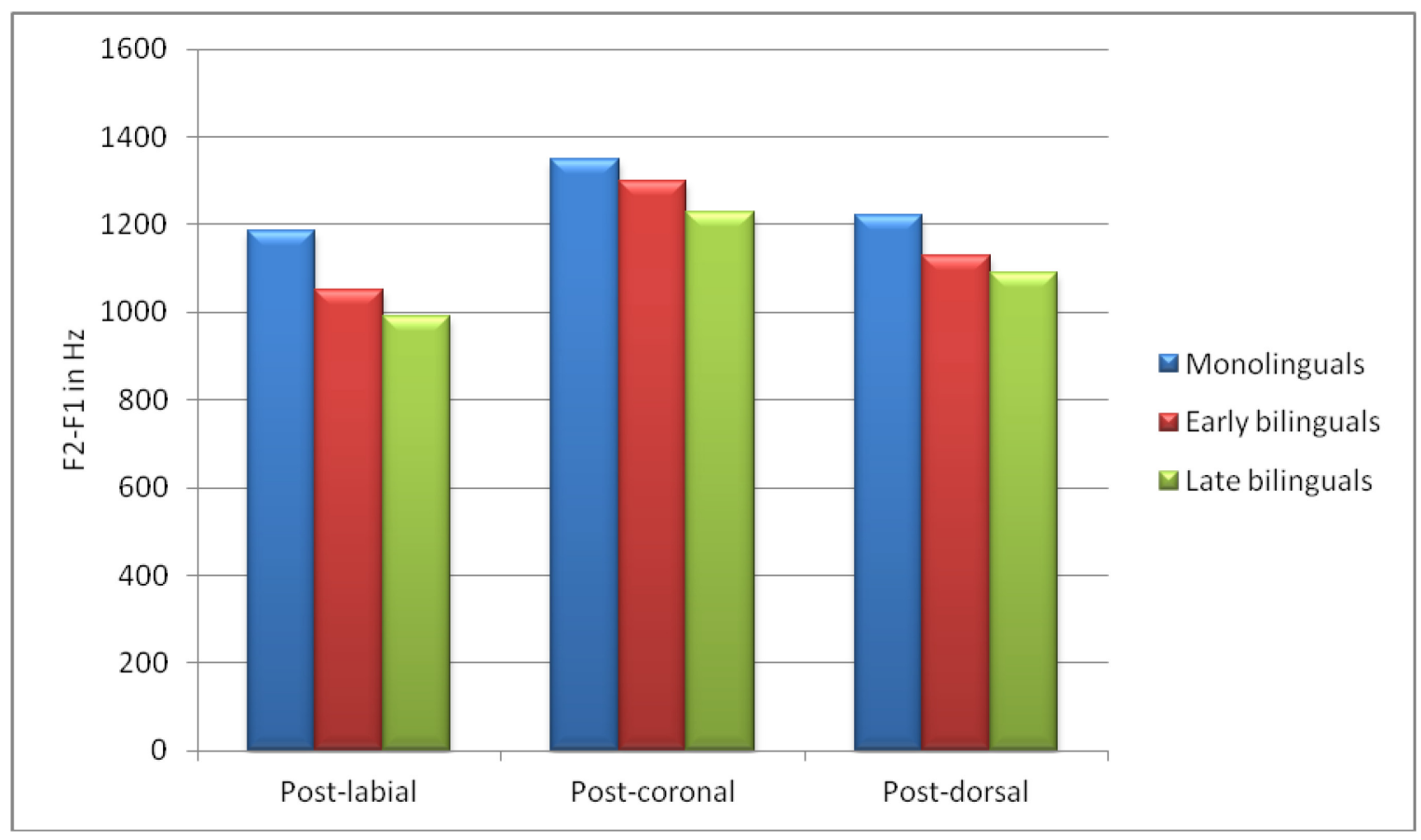

At first glance, the F2-F1 structures display a more uniform pattern overall, as all three populations tend toward a 'post-labial < post-dorsal < post-coronal' ranking of the F2-F1

\footnotetext{
${ }^{7}$ For a complete list of the average means and standard deviations by place of
} articulation, see Appendix F. 
position. The noticeably higher F2-F1 vowels across post-coronal environments is indicative of vowel fronting, a progressive assimilation technique caused by adjacency to a coronal consonant. The application of a one-way ANOVA repeated measures test further reveals several inconsistencies that the previous figure fails to elucidate.

With regard to the monolingual group, it becomes apparent that there is a failure to reach statistical significance between the post-labial and post-dorsal groups $(p=.129)$. The same pattern is found among late bilinguals, who also fail to reach significance between the post-labial and post-dorsal groups $(\mathrm{p}=.146)$. It should be noted that significance between post-dorsal and post-coronal schwas, the late bilingual group barely reaches significance $(\mathrm{p}=.048)$, which points to what is essentially a haphazard ordering of vowel qualities among late bilinguals.

What is most intriguing among this data set is that early bilinguals, again, are the only group to produce statistical significance between all three places of articulation. If monolinguals were to consistently collapse two categories in terms of vowel quality production, it is counterintuitive to believe that labial and dorsal areas of the oral cavity would find themselves sharing coarticulatory features. Figure 3.1.i-k below illustrates the relative position in the mouth of each group's post-labial, post-coronal, and post-dorsal means. 
Figure 3.1.i Comparison of the position of schwa in CV\# position among monolinguals.

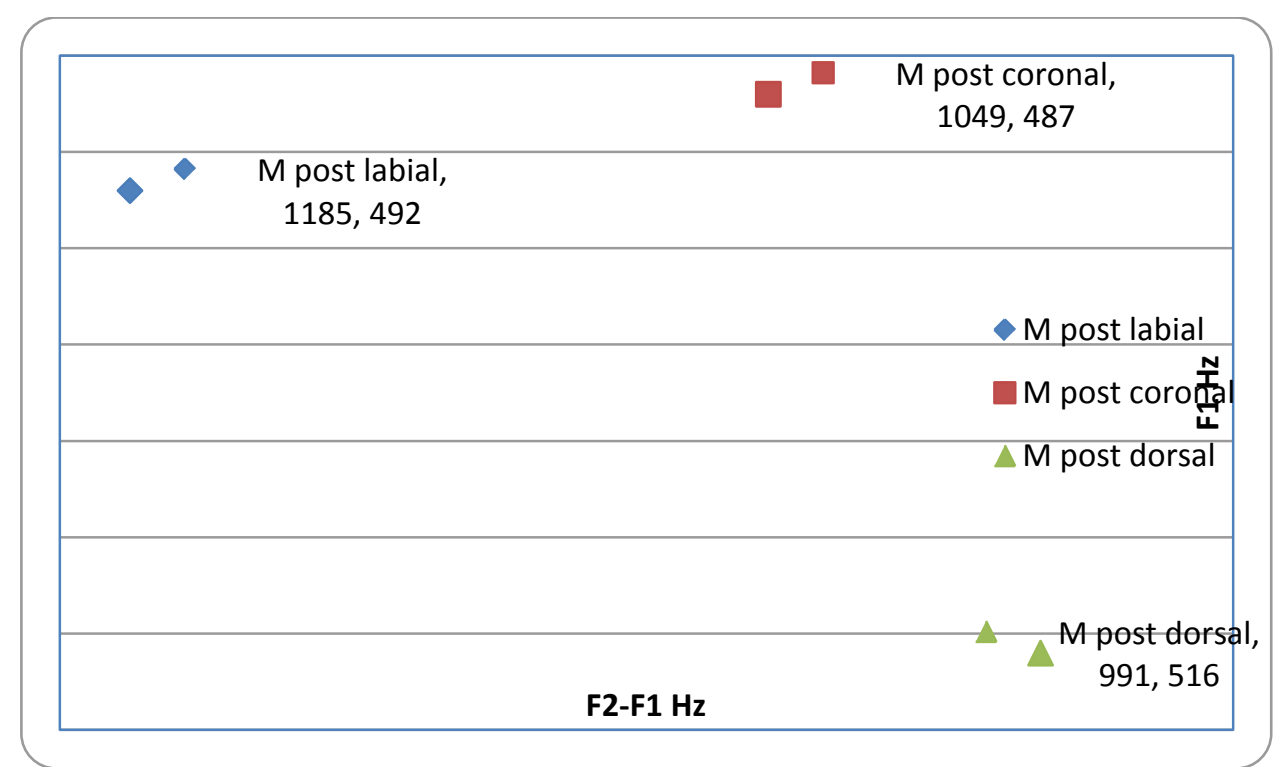

As demonstrated in Figure 3.1.i the tendency of monolinguals is to produce a significantly higher and more "fronted" schwa than occurs in either post-labial or postdorsal environments. While this is to be expected, it is interesting to note that the difference between post-dorsal and post-coronal schwas did not reach statistical significance, though both were significantly different from post-labial schwas. Figure 3.1.j compares these positions among the early bilingual population. 
Figure 3.1.j A comparison of the position in the mouth of schwa in $\mathrm{CV \#}$ position among early bilinguals

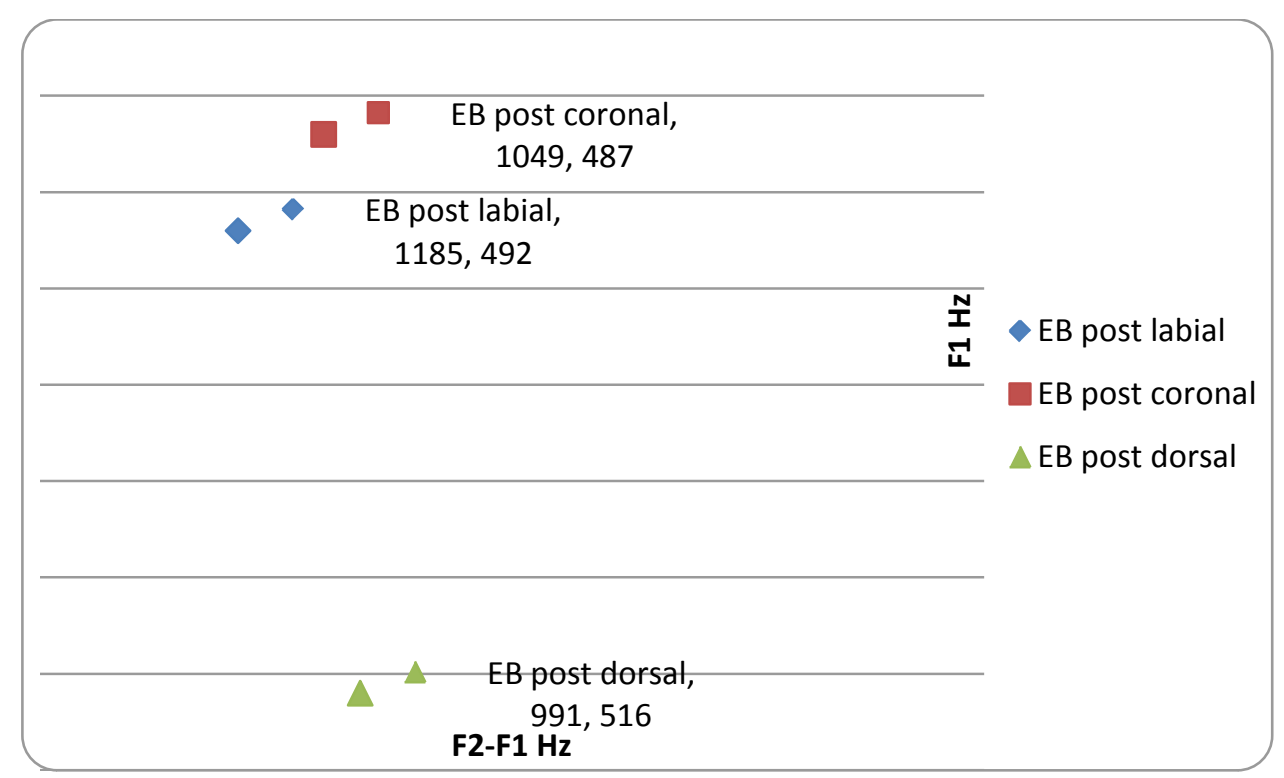

Figure 3.1.j presents a remarkably similar picture to that of monolingual speakers. These results establish with reasonable certainty that early bilinguals are capable of perceiving mild differences in schwa production across a variety of post-consonantal environments. It may be the case that early bilinguals overcompensate for these mild differentiations, however, as all three $\mathrm{CV} \#$ environments were significantly different only in this group of participants. Figure 3.1.k illustrates the production values of these schwas in CV\# position as produced by late bilinguals. 
Figure 3.1.k A comparison of the position in the mouth of schwa in CV\# position among late bilinguals

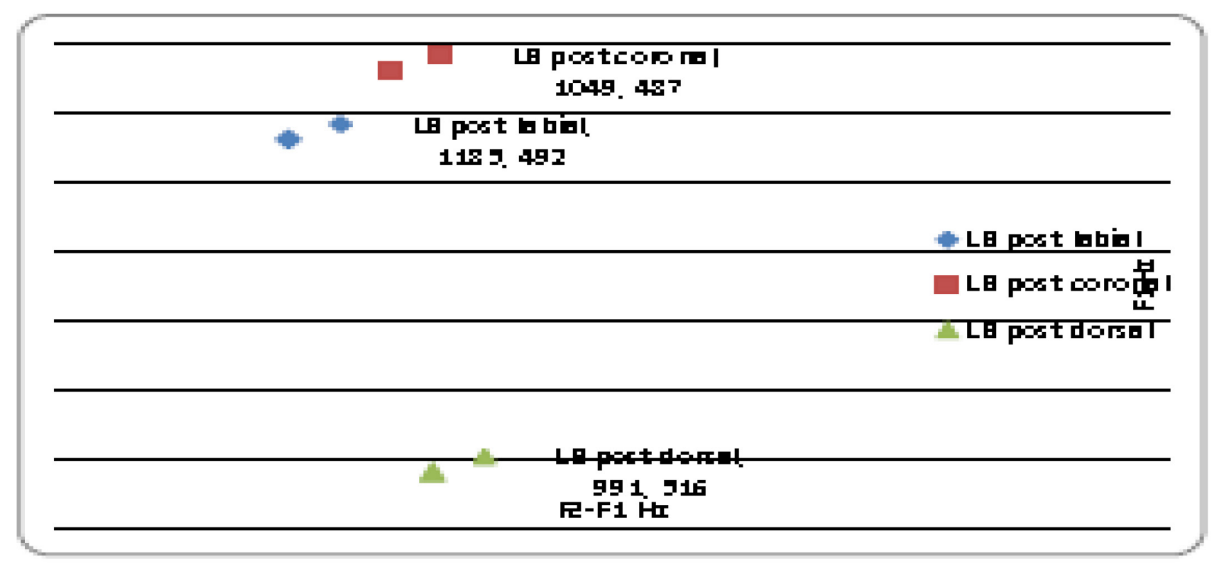

Upon first glance the pattern for late bilinguals appears to be the same. Truly, the overall production pattern for late bilinguals mirrors that of monolingual and early bilingual participants. However, in late bilinguals none of the categories, post-labial, post-coronal, or post-dorsal, are significantly different from one another. This implies a lack of perception with regard to the subtleties of variation in schwa production. These three figures highlight two important generalizations regarding the phonetic environment of schwa: The post-dorsal environment produces a lower vowel in all three participant groups (as demonstrated by observably higher F1 values) and the post-coronal environment invariably produces a more fronted vowel, as witnessed by higher F2-F1 values. Figure 3.1.1 provides a conclusive visual representation of the variation one finds in each of the average $\mathrm{CV} \#$ environments across groups. 
Figure 3.1.l Across-groups comparison of the average values

of among three places of articulation

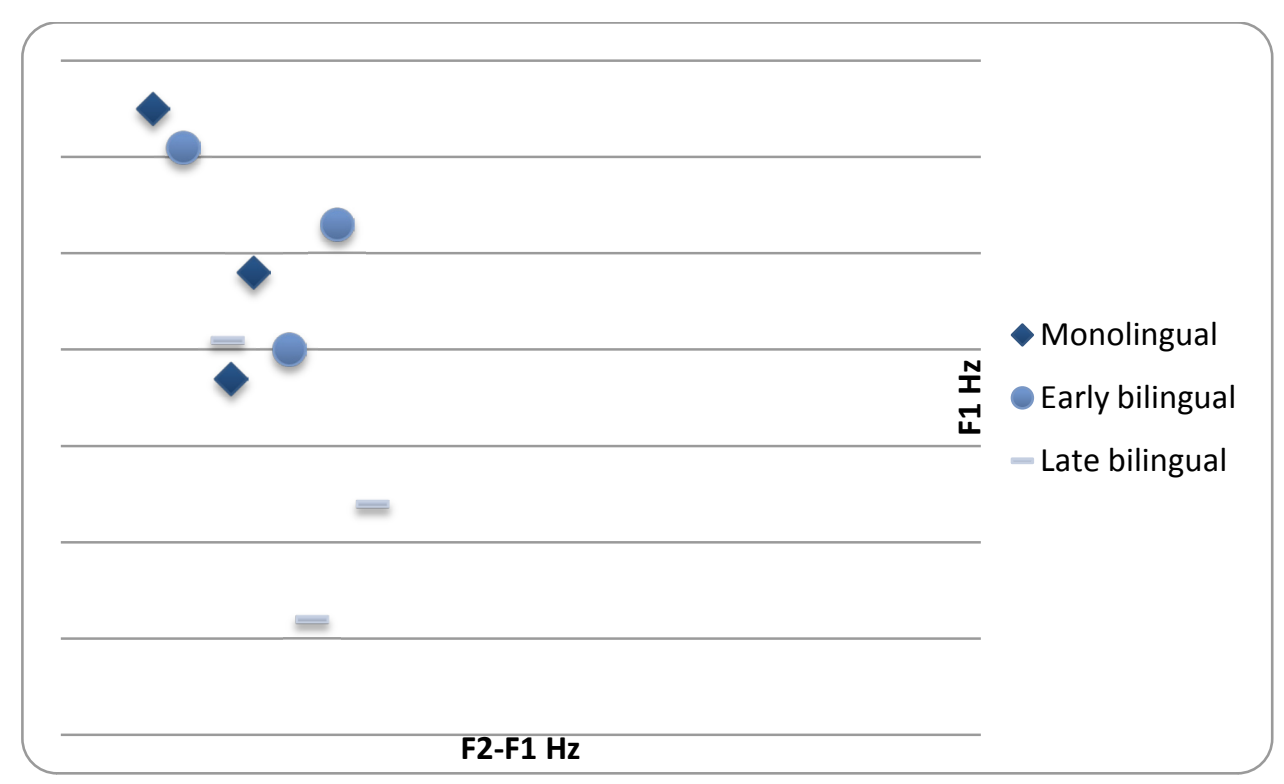

This figure clearly demonstrates that while the numbers across groups appear slight, an overall pattern exists whereby monolinguals produce slightly higher and more fronted schwas across all three environments, early bilinguals closely approximate these values, and late bilinguals are produce schwas which are lower and farther back in the oral cavity than either monolinguals or early bilinguals.

\subsection{Experiment II}

This experiment examines the duration of word-internal schwa in a variety of intersentential environments. The target reduced vowels in this instrument (see Appendix D) are classified as either "deletable" or "non-deletable." Deletable schwas are vowels which have undergone multiple layers of reduction to become mid-central lax articulations due to their position adjacent to a stressed syllable. Reduced vowels are particularly vulnerable to deletion when morphological alterations create adjacent syllables containing a [ə] nucleus. The schwa may then undergo [optional] deletion 
which collapses the vowel nucleus, thereby reducing the number of syllables in the word by one.

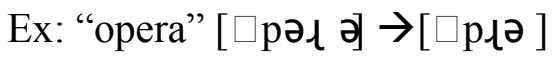

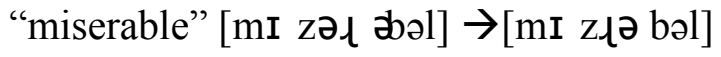

By contrast, nondeletable schwas are vowels which reduce in pretonic and posttonic environments; however, the reduced vowel cannot adopt a null value. In many environments, preservation of the syllable nucleus prevents adjacent primary and secondary stress. Furthermore, nondeletable schwas do not occur adjacent to other reduced vowels, and so their preservation contributes to the "galloping rhythm" of American English.

The first section of this experiment analyzes patterns in the duration of deletable and nondeletable schwas within and across all three linguistic groups. Results for the late bilinguals are included, but consideration must be maintained of the fact that many, if not most, of the target vowels produced by this group were closer to $/ \mathrm{a} /$ and $/ \wedge /$. Therefore, any intergroup comparison against monolingual or early bilingual /a/ should be interpreted with this in mind.

Section 3.2.1 provides an intragroup and intergroup comparison of the temporal qualities of deletable and nondeletable categories of sounds. Upon removal of the control sentences, included for the purpose of varying tempo and retaining attention to the instrument, each group retained six target sentences which were uniformly phrased “Don’t say ___ _ say ___ _.” (Appendix C) Utilization of a carrier sentence controls for prosodic features such as stress and intonation which could influence the 
duration of reduced vowel production. As is illustrated in section 3.2.2, this construction also allows for an accurate comparison of semantically-related word pairs by removing all extraneous features.

The second portion of this experiment seeks to determine whether the duration of seemingly homophonous [ə] in semantically-related words (i.e., "probably" vs. “probability”) differs significantly on an individual level. Results are analyzed by splitting the target words off into semantically related pairs, whose schwa production is analyzed for significance using paired-sample t-tests. It is believe that the uniform conditioning of sentences within the instrument as "Don't say , say allows for a legitimate comparison between word pairs due to the neutralization of external contrasts between the environments.

\subsubsection{Comparison of reduced vowel lengths in word-internal environments}

This experiment is a within-subjects test to uncover whether measurably significant differences in duration exist within each group. First the mean value for monolingual duration of deletable and nondeletable schwas was calculated to determine 1) if a difference in duration exists between the two categories and 2) is this difference statistically significant? Within this group, deletable schwas last an average of $.035 \mathrm{~ms}$, compared with $.045 \mathrm{~ms}$ for nondeletable schwas. The observable difference between deletable and non-deletable schwas easily achieves statistical significance $(\mathrm{p}=.008)$. Equivalent values were extracted from early and late bilingual populations, which are displayed for comparison in figure 3.2.a. 
Figure 3.2.a Across-group comparison of duration in deletable and nondeletable schwas

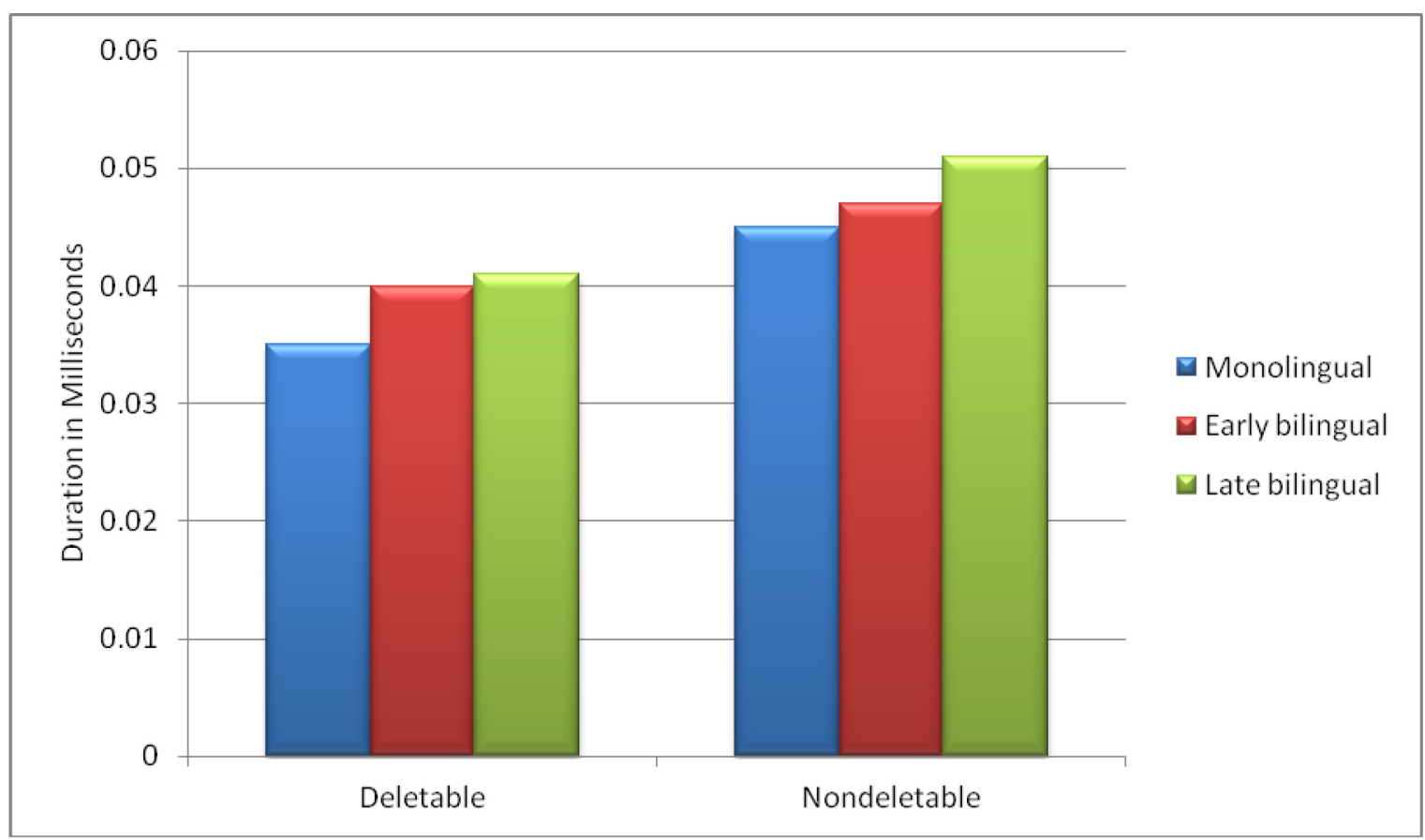

In each group, the difference between deletable and nondeletable schwas is statistically significant. Early bilinguals average $.040 \mathrm{~ms}$ in deletable environments, compared with $.047 \mathrm{~ms}$ in nondeletable, whereas late bilinguals display means of $.041 \mathrm{~ms}$ and $.051 \mathrm{~ms}$ respectively. These means confirm a preference for shorter reduced vowels in deletable situations. Furthermore, it appears from the data above that both deletable and nondeletable schwas are uniformly longer in duration when produced by late bilinguals.

The decision was made to compare the duration of deletable schwas and nondeletable schwas between monolinguals and early bilinguals using a one-way ANOVA test, performed in place of a paired-sample T-test due to the anticipated similarity in results. Table 4.2.a illustrates the results of a comparison between the monolingual and early bilingual groups. 
Table 3.2.a. Comparison of deletable and nondeletable vowel durations across populations ANOVA

\begin{tabular}{|ll|r|r|r|r|r|r|}
\hline & & $N$ & Mean & $\begin{array}{c}\text { Std. } \\
\text { Deviation }\end{array}$ & Std. Error & $\begin{array}{c}\text { Minim } \\
\text { um }\end{array}$ & $\begin{array}{c}\text { Maxim } \\
\text { um }\end{array}$ \\
\hline AvgDeletableDuration Avg & $1 \mathrm{M}$ & 25 & .035 & .008 & .002 & .022 & .050 \\
Deletable Duration & $2 \mathrm{E}$ & 25 & .040 & .007 & .001 & .025 & .052 \\
& Total & 50 & .037 & .008 & .001 & .022 & .052 \\
\hline AvgNondeletableDuration & $1 \mathrm{M}$ & 25 & .045 & .008 & .002 & .031 & .067 \\
Avg Nondeletable & $2 \mathrm{E}$ & 25 & .047 & .013 & .003 & .030 & .095 \\
Duration & 50 & .046 & .010 & .001 & .030 & .095 \\
& Total & 5030 & & & & & \\
\end{tabular}

This across-group comparison produces significant levels of difference in the "deletable" group $(\mathrm{p}=.030)$, yet fails to reach statistical significance in duration for the "nondeletable" category. This variation in reduced vowel production in deletable environments may well be one of the indicators of a perceived foreign accent.

Late bilinguals were not compared for significant difference in duration against monolinguals and early bilinguals due to the abundance of target vowel performance errors noticed during the data collection process; the target substitutions in these cases was often /a/, a vowel which, in comparison with [ə], would yield little insight into the current research question. Nevertheless, it is worth noting that the average duration of vowel productions for late bilinguals appears to be markedly different from that of monolinguals, yet there is little discrepancy in the mean productions between early and late bilinguals. Among all three participant groups the results indicate that [ə] is not entirely homophonous in deletable and nondeletable environments with regard to duration. 


\subsubsection{Semantically-related words}

In the final section of this experiment, word pairs ( semantically-related words containing deletable/nondeletable items such as "general"/"generality") were analyzed using paired-sample T-tests. This test is applied to determine if the differences in data from exactly two groups reaches statistical significance. This research question requires a binary analysis of each pair to assess significant differentiations in duration of schwa. Table 3.2.b presents the results of paired-sample t-tests ${ }^{8}$. This table highlights the statistically significant findings between the aforementioned pairs. Interestingly, none of the pairs shows statistical significance in the late bilingual group.

Table 3.2.b Paired sample T-tests of semantically related word pairs

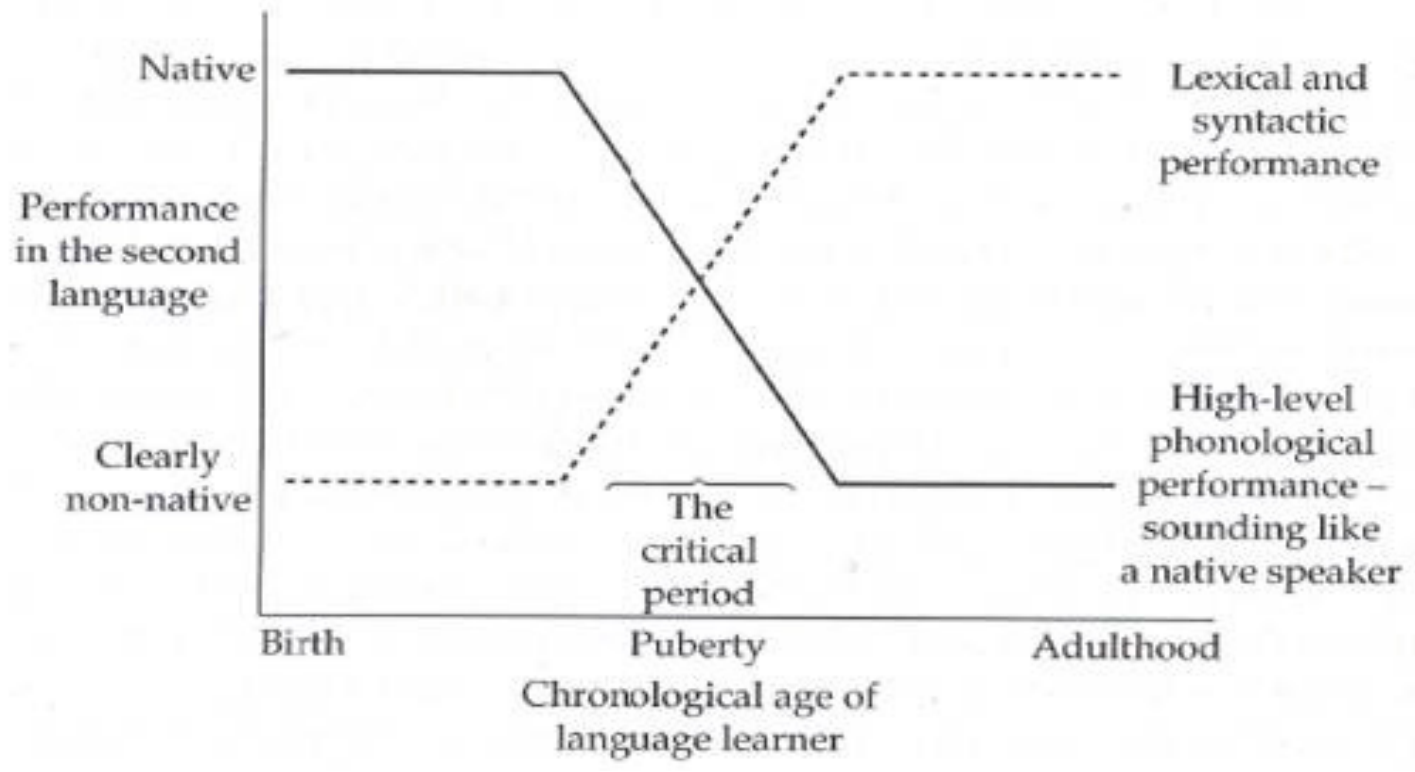

A lack of significance within the late bilingual group is likely the result of targetlessness in the articulation of medial schwa. Furthermore, the complete lack of statistical

${ }^{8}$. For a comprehensive list of each word pair comparison, see Appendix E. 
significance in any of the targets indicates a lack of methodical pronunciation of medial schwa values. These indistinguishable values are completely divergent from the behavior of monolinguals, who registered statistically-significant differences in five of the six tested word pairs. Early bilinguals pattern somewhere in between monolinguals and late bilinguals, with two of six tested environments ("testament"/ "testimony" and "imaginative"/ "imagination") reaching a level of significance.

\subsection{Summation of the results}

The six experiments in this chapter were conducted with the aim of determining which patterns of bilingual speech varied significantly across populations. Patterns in variation were confirmed most often in experiments which measured duration, rather than vowel qualities per se. Statistical analyses indicate that the common factor among all of these experiments is that the three participant groups pattern variables in different ways. Whereas across-group comparisons may render differences too slight to register statistical significance, differences within groups may provide insight as to how speakers will synthesize target words within a given category. The following chapter provides final commentary on these findings, which are incorporated into the larger discussion of L2 perceptual theory. 


\section{CHAPTER 4. Conclusion}

\subsection{Theor etical I mplications for R educed V owel Production}

Having amassed a considerable quantity of data concerning vowel reduction processes, the current section seeks to integrate these data into two prominent theories of L2 acquisition. Section 4.1.1 engages Flege's Speech Learning Model (SLM hereout) in a discussion of L2 achievement in bilinguals who have been L2 speakers for many years. Section 4.1.2 examines the conclusions of this study within the framework of Kuhl's Native Language Magnet Model (NLM hereout). Kuhl's model, outlining the progression of L2 sound perception through perceptual mapping techniques, is analyzed for compatibly with the current data, particularly that of late bilinguals (see Escudero, 2007).

Section 4.2 articulates several generalizations that can be made regarding Spanish-English bilinguals' production of reduced vowels. Section 4.2.1 details the patterns one expects to find in vowel quality production across populations, whereas section 4.2.2 addresses the overarching trends found in the current study regarding vowel duration. Conclusions are drawn from the second experiment, highlighting medial schwa in intersentential environments, in section 4.2.3. Final thoughts on the research design and execution of the experiment, as well as recommendations for future study, conclude the current study in section 4.3.

\subsubsection{Speech L ear ning Model}

Flege's SLM postulates that late bilinguals will experience greater difficulty discerning the phonetic features of similar phones. In essence, rather than being perceived as separate sounds, these non-distant segments may come to be processed as 
"positional-define allophones," and the distinction remains unlearned by the L2 speaker. Flege does not propose a criteria for the boundaries of what constitutes a phoneticallydistant sound, thus creating ambiguity with regard to which sounds may qualify as "similar." While the lack of distance is obvious in sounds such as /t/ and / /, the situation is a bit more complex with regard to reduced vowels.

The relationship between L2 target schwa and L1 vo

/ example. The complete neutralization of vowel height and backness features creates an environment where multiple vowels are acceptable candidates for L1 substitution. As a result of the absence of any vowel occupying the central region in Spanish, it is likely that, as the SLM posits, L2 learners do not perceive schwa as a central vowel. What is perhaps most interesting is that the late bilingual speakers in this study did alternate the L1 vowel substitution to more closely approximate the features displayed by native speakers. Specifically, in situations where native speakers produced $[\dot{\mathfrak{t}}]$ (as in "judges"), late bilinguals were prone to substitute the positional allophone [ $\varepsilon$ ], which is an allophone of /e/ that is produced closer to the target [ə]. However, in word-final position late bilinguals who failed to reduce the vowel uniformly substituted [a], which is in harmony with native speakers' higher F1 values in this category.

Flege argues that perception problems are language-specific, and that it is the available L1 phonemic options a speaker has to choose from which govern the L2 substitution. The current study supports this view in light of the coinciding of substitution judgments and the Spanish vowel inventory made by the majority of late bilinguals. As a final point to reconcile regarding the SLM, Piske, Mackay, and Flege 
(2001) have found that L2 speakers who use their L1 infrequently pattern much more like native speakers than L2 speakers who often employ their native language. The hypothesis that people who use their L1 infrequently would perform better was not easily testable in the current experiment because the location (Miami) requires most people to use Spanish daily. This linguistic environment creates a situation where all of the late bilingual participants engage in regular L1 usage - a factor which may have contributed to lower success rates in $\mathrm{L} 2$ reduced vowel production.

\subsubsection{Native $L$ anguage Magnet Model}

In adapting her NLM to L2 acquisition, Kuhl proposes that the existence of an L1 perceptual filter creates difficulty because later learning is constrained by the initial mappings ingrained in the neural structure (Escudero, 2007). As language learning continues into adulthood, incoming L2 sounds will be drawn to the perceptual magnets already ingrained in the learner's brain. In order for new perceptual categories to form, a sound must be distinguishable from all other preexisting magnets, otherwise perceiving and acquiring the new segment are met with difficulty.

In brain imaging studies, the conclusion has been reached that only adult bilinguals who acquire both languages early in life possess overlapping regions of the brain when processing the two languages (Escudero, 2007). Therefore, Kuhl postulates that adult bilinguals strive to maintain two separate perceptual systems to be activated depending upon the speaker's language mode. It is the opinion of the current study that this failure to fully cement dual perceptual systems is less the cause of failure to reduce vowels, than is simple L1 transfer of the [Spanish] premise that all vowels are full 
vowels, and their articulation as such is integral to maintaining the staccato syllable structure which is the preferred speech rhythm for late bilinguals.

\subsection{Generalizations regar ding $L 2$ r educed vowel production}

\subsubsection{Vowel quality distinctions}

The current study supported several aspects of Flemming's $(2007,2009)$ studies on predictable distribution of certain vowel qualities in schwa. It was the finding of the current study that all three participant groups distinguished between the plural morpheme $\{-a z\}$ being a higher central articulation (closer to $[\dot{+}]$ ), with the possessive morpheme $\{-$ əz \} characterized by slightly lower F2 and higher F1 values. These predictable differences support the rationale that "Rosa's roses" are not truly homophonous words, and that a distinction in transcription of these reduced vowels would more accurately reflect these differences.

It is not the case, however, that the possessive morpheme $\{-\partial z\}$ is simply "wordfinal $[a]+/ s /$ " as Flemming claims. Findings here indicate that word-final schwa was characterized by higher F1 formants and lower F2 formants than one would find in possessive endings such as the pair "Marsha"/"Marsha's." Higher F1 and lower F2 formants signify that word-final schwas are produced both lower and farther back in the mouth than their possessive counterparts. The trend that word-final schwas are produced lower and more centrally than the plural and possessive categories is generally consistent in all three participant groups. Late bilinguals, however, have noticeably higher F1 formants (indicating a lower vowel) in this position which, coupled with longer duration, argues for perception of word-final [a], particularly in cognates such as "sofa." However, late bilinguals follow the same pattern as native speakers in F2-F1 values: Word-final < 
Possessive $<$ Plural, leading to the conclusion that even adult learners perceive that schwa in the possessive morpheme and in word-final position are separate constructions.

Monolinguals present a clear picture of the ideal relationship between F1 (height) and F2 (backness) values in achieving native-like pronunciation. An inverse relationship exists between the F1 values ranked "plural < possessive $<$ word-final" and F2 values which prefer "word-final < possessive <plural." This inverse relationship is integral to establishing accent-free pronunciation of the central vowels (and their allophones) in American English. Figure 4.2.a provides a mapping of spectral measurements onto a protypical vowel chart in SAE.

Figure 4.2.a Prototypical F1 and F2 values for Standard American English vowels

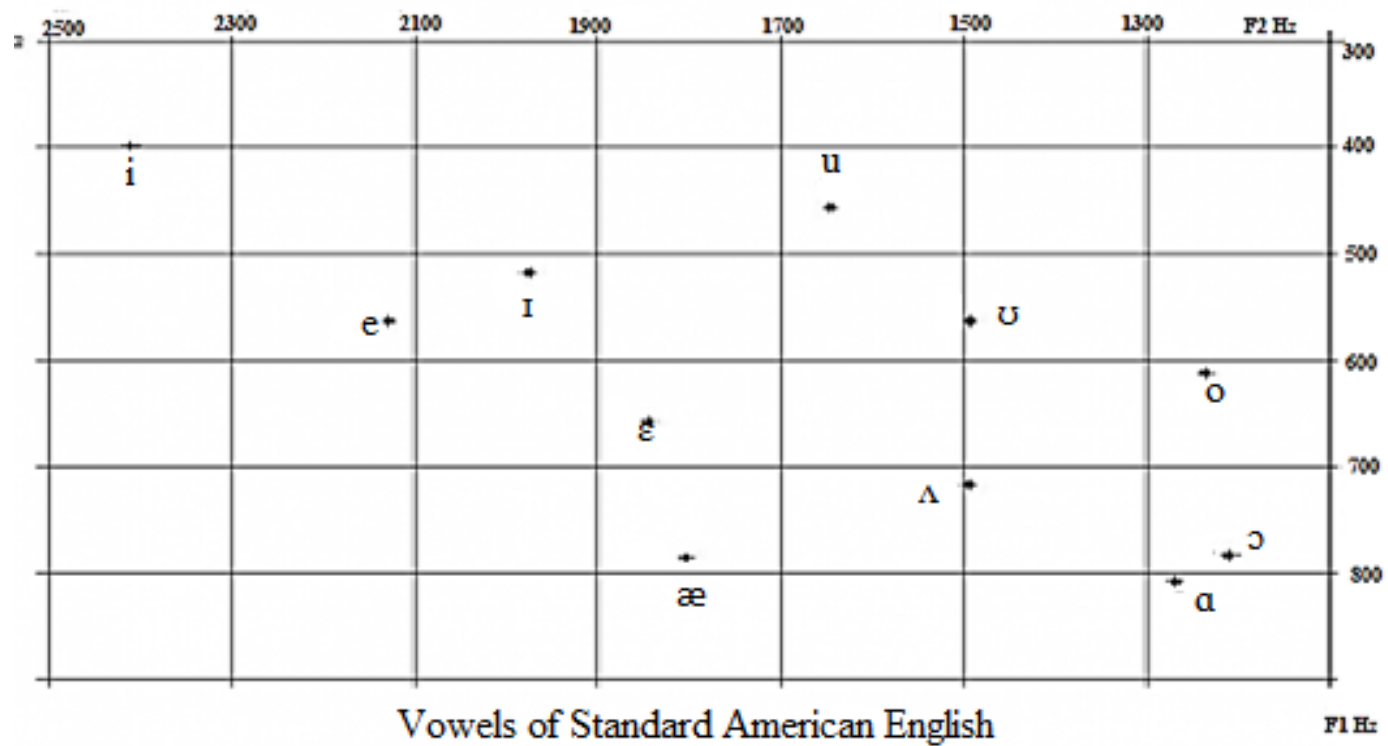

The chart above illustrates the fact that higher F2-F1 values [in plural and possessive morphemes] in both bilingual groups indicates that these speakers may be approximating mid-front vowel $[\varepsilon]$ instead of producing a truly neutralized value. Having established this pattern of perception, the next step in the research was to 
determine to what effect progressive assimilation would affect the vowel qualities of schwa in word-final position. It became apparent from the onset that no participant group recorded even F1 and F2-F1 values across the three groups: post-labial, post-coronal, and post-dorsal. There were slight differentiations in the F1 values, as monolinguals and late bilinguals followed the pattern: post-dorsal $>$ post-labial $>$ post-coronal, with early bilinguals reporting post-dorsal $>$ post-coronal $>$ post-labial for F1. This section of the experiment was exploratory, however, and to extract generalizations the instrument would have to be greatly expanded.

Average F2-F1 values in word-final environments present a more unified pattern. Schwas which occur in post-coronal environments display the highest F2-F1, which is believed to be the result of vowel fronting due to progressive assimilation. Predictably, post-dorsal environments displayed the lowest F2-F1 values, as velar consonants do not facilitate fronting. This portion of the experiment was conceived as a subset of the larger experiment on vowel qualities in plural, possessive, and word-final environments further research is necessary to establish conclusions on progressive assimilation in schwa production.

\subsubsection{Variation in schwa duration}

The intricate variations each participant group employs with regard to vowel duration became one of the most interesting parts of the study. Native speakers further confirmed the hypothesis that plural $\{-a z\}$ and possessive $\{-a z\}$ are not homophonous by reporting statistically significant differences as follows: word final $>$ plural $>$ possessive. Early and late bilinguals do not distinguish these differences so clearly, nor do these groups follow the same patterns amongst themselves. Early bilinguals do not distinguish 
between word-final schwa and the plural morpheme, though possessive morphemes are shorter. Late bilinguals, on the other hand, produce longer word-final schwas, but significant difference between the plural and possessive morphemes is absent. The inability of bilinguals to replicate native speakers' patterns of difference in reduced vowel duration may be a contributing factor to the perception of a foreign accent.

A few words are also in order concerning duration of the various subsets ${ }^{9}$ of word-final schwa. While all three groups conformed to the pattern post-dorsal > postcoronal $>$ post-labial, only early bilinguals had significant differences between all three environments. Native speakers did not reliably produce a difference between post-dorsal and post-coronal durations, though post-labial was invariably the shortest duration. It may be the case that monolinguals' propensity to truly reduce the features of word-final vowels nullifies the distinction between dorsal and coronal, whereas speakers who are only approximating vowel reduction are more vulnerable to the effects of surrounding consonants. These assimilatory features are further examined in section 4.2.3, which provides commentary on the durational aspects of medial schwa.

\subsubsection{Semantically-related word pairs}

It was hypothesized at the onset of the study that monolinguals possess subconscious phonological knowledge of deletion processes and would, therefore, make a distinction in duration between an optional schwa ( deletable) and schwas which are required to maintain a mandatory syllable nucleus (nondeletable). Since bilingual

\footnotetext{
${ }^{9}$ Post-labial, post-coronal, and post-dorsal
} 
participants did not delete schwas except in rare cases ${ }^{10}$, it was unknown whether or not they would be sensitive to temporal variations. As was expected, the study confirmed that monolinguals indeed make significant distinctions between deletable and nondeletable schwas. Surprisingly, however, this distinction was made within all three participant groups. The question then became whether or not the production of these values (i.e. monolinguals' deletable duration vs. early bilinguals' deletable duration) differed across groups. In these tests, results attested to less uniformity, as only the duration in deletable schwas which was significant was between monolingual and early bilingual groups; none of the nondeletable differences were significant across groups. To conclusively test whether or not there is a generalizable rule concerning deletable schwa duration across groups, it is necessary to increase the size of the instrument and replicate the experiment.

These test words were conceived of as semantically-related pairs in order to control for all extraneous factors which could create sentential variation. The question was then posed whether or not a significant difference arises in the production of schwa in these phonetically-similar constructions. The results indicated quite divergent patterns which have strong implications for the prediction of a foreign accent. Monolinguals produced significant differences in duration in 5 out of 6 word pairs. Early bilinguals produced significant differences in 2 out of 6 pairs, whereas late bilinguals produced none. Alteration of this target [ə] provides the listener with a clue as to the ultimate meaning of the word, thus aiding in intelligibility. Failure to provide this alteration

\footnotetext{
${ }^{10}$ Early bilinguals often reduced "literal" to [li trəl] and "general" to [dz\&nrəl]
} 
requires the listener to delay comprehension and results in the perception of a nonnative speech pattern.

\subsection{L imitations and Extensions}

The current study sought to examine reduced vowel production in SpanishEnglish bilinguals across a variety of environments. As information was processed, other interesting variables (such as the coarticulatory effects of the preceding consonant) came into question, and were examined briefly in the course of this study utilizing participant groups who were already assembled. This subset of the experiment should be considered exploratory in nature, as it is imperative to amass more than two target sentences for each environment in order to draw assess the validity of findings presented here. Further plans for research include the expansion of the instrument of target sentences in deletable/nondeletable environments from six sentences in each category in hopes of defining a more refined phonological rule than "deletable schwas are shorter in duration than those which cannot be deleted." Future studies may wish to focus only on this aspect of schwa production.

Another area of the study which may be altered in the future is the method of eliciting these productions. Having participants read sentences from a computer screen raises issues concerning their ability to produce sentences at normal speaking rates slower, more formal speech styles are not conducive to vowel reduction. Harrington (2010) postulate that speakers make moment-by-moment decisions regarding the listener's need for information, and when this need is high (as in a formal experiment setting) the speaker will increase articulatory effort. The use of the carrier sentence

“Don’t say __ _ say ___ _ ensured uniformity in measuring spectral analysis; 
however, this sentence also rendered target word prediction to be impossible, which these authors postulate to result in hyperarticulation of the targets.

One method which has been recommended is the "delayed repetition technique" whereby a participant listens to a prerecorded dialogue and then repeats one of the recorded sentences when prompted. There is some concern regarding the possibility of hindering late bilinguals by using this technique to assess reduced vowels, as the added stress of having to answer correctly might cause additional stress to this participant group. It will be interesting to note the outcomes of reduced vowel production under this procedure.

Further study may also wish to focus on a demographic of bilinguals who are more divorced from the L1 community. In Miami there is always the possibility that bilinguals never received adequate L2 American English input to learn the sort of vowel reductions which characterize monolingual speech. The pervasive bilingualism of this city creates the possibility that L2 American English was acquired without proper input, and that the situation was not remedied in a bilingual school and social environment. Comparison of these results to those of bilinguals living immersed in the L2 should provide more normative results. Nevertheless, the current study has been able to provide several keen insights regarding the ability of high-functioning bilinguals to perform a key phonological process of American English while in L2 mode. This study has also proven, from a variety of measures, that early L2 acquisition is a predictive factor in the ability of a bilingual to produce native-like segments and obey key phonological processes as demanded by the ambient language. 


\section{References}

Best, C. and Tyler, M. 2007. "Nonnative and second-language speech perception." In O.S. Bohn and M. Munro, (eds) Language Experience in Second Language Speech Learning. Philadelphia: John Benjamins Publishing Company.

Birdsong, D. 1999. Second Language Acquisition and the Critical Period Hypothesis. Mahwah, NJ: Lawrence Erblaum Associates.

Browman, C. and Goldstein, L. 1990. "Targetless schwa: An articulatory analysis." In G. Docherty and D. Ladd, (eds) Gesture, Segment, Prosody. Cambridge University Press, 194-219.

Chomsky, N. and Halle, M. 1968. The Sound Pattern of English. New York: Harper \& Row.

Dalby, J. 1986. Phonetic Structure of Fast Speech in American English. Bloomington, IN: University of Indiana Press.

Escudero, P. 1987. "Second language phonology: The role of perception." In M. Pennington, (ed) Phonology in Context. Palgrave Macmillan, 115-125.

Flege, J. 1987. "The production of 'new' and 'similar' phones in a foreign language: evidence for the effect of equivalence classification." Journal of Phonetics, 15, 47-65.

Flege, J. 1991. "Age of learning affects the authenticity of voice onset time (VOT) in stop consonants produced in a second language." Journal of the Acoustical Society of America, 89. 395-411.

Flege, J. 1995a. "Second language speech learning theory, findings, and problems." In Strange, W., (ed) Speech Perception and Linguistic Experience: Issues in CrossLanguage Research. Timonium, MD: York Press, 78-104.

Flege, J. 2005. "Origins and development of the Speech Learning Model." $1^{\text {st }}$ ASAWorkshop on L2 Speech Learning. Simon Frasier University, Vancouver: April 14-15, 2005. Oral Presentation.

Flege, J., Bialystok, D., Mack, M., Sung, H., and Tsukada, K. 2006. "Degree of foreign accent in English sentences produced by Korean children and adults." Journal of Phonetics, 34, 153-175.

Flege, J. and Bohn, O.S. 1989. "An instrumental study of vowel reduction and stress placement in Spanish-accented English." Studies in Second Language Acquisition, 11, 35-62. 
Flege, J., Frieda, A., and Nozawa, T. 1997. "Amount of native-language (L1) use affects the pronunciation of an L2." Journal of Phonetics, 25, 169-186.

Flege, J. and Hillenbrand, J. 1984. "Limits on phonetic accuracy in foreign language speech production." Journal of the Acoustic Society of America, 76, 692-707.

Flege, J. and Mackay, I. 2004. "Effects of the age of second-language (L2) learning on the duration of L1 and L2 sentences: The role of suppression." Applied Psycholinguistics, 25, 373-396.

Flemming, E. 2009. "The phonetics of schwa vowels." In Minkova, D., (ed) Phonological Weakness in English. Hampshire, England: Palgrave Macmillan Publishing, pgs in printing.

Flemming, E. and Johnson, S. 2007. "Rosa's roses.” Journal of the International Phonetic Association, 37, 83-96.

Fokes, J. 1993. “The Elusive/Illusive Syllable.” Phonetica, Vol. 50, No. 2: 102-123.

Hammond, R. 1999. The Sounds of Spanish: Analysis and Application. Purdue University Press.

Harrington, J. 2010. “Acoustic Phonetics.” In Hardcastle, W.J., Laver, J.L., and Gibbon, F.E., (eds). (2010). The Handbook of Phonetic Sciences. $2^{\text {nd }}$ edition. WileyBlackwell Publishing. 91-93.

Hillenbrand, J.M., Clark, M.J., Neary, T.M. 2001. "Effects of consonant environment on vowel formant patterns." Journal of the Acoustical Society of America, 109 (2), 748-763.

Ioup, G. 2008. "Exploring the role of age in the acquisition of a second language phonology." In Hansen-Edwards, J. and Zampini, M., (eds) Phonology and Second Language Acquisition. Philadelphia: Johns Benjamin Publishing Company, 176-203.

Kondo, Y. 1994. "Targetless schwa: Is that how we get the impression of stress timing?" Proceedings of the Edinburgh Linguistics Conference, 1994, 63-76.

Kuhl, P. 2000. “A new view of language acquisition." Proceedings of the National Academy of Science, 97, 11850-11857.

Lenneburg, E. 1969. “On explaining language.” Science, 125, 635-643.

Lindblom, B Björn. 1963. "Spectrographic study of vowel reduction." Journal of the Acoustical Society of America, 35 (11), 517-525. 
Olive, J., Greenwood, A., and Coleman, J. 1992. Acoustics of American English: A Dynamic Approach. Springer Publishing.

Patkowski, M. (1990). “Age and accent in a second language: A reply to James Emil Flege.” Applied Linguistics, 11 (1), 73-89.

Patkowski, M. (1994). "The critical age hypothesis and interlanguage phonology". In Yavas, M. (ed.), First and second language phonology. San Diego: Singular Publishing Group, 205-221.

Piske, T., Mackay, I., and Flege, J. 2001. "Factors affecting degree of foreign accent in an L2: a review." Journal of Phonetics, 29, 191-215.

Scovel, T. 1988. A Time to Speak: A Psycholinguistic Inquiry into the Critical Period for Human Speech from Yavas, M. (2011). Applied English Phonology. Oxford: Wiley-Blackwell Publishing.

Stevens, K.N. and House, A.S. 1963. "Perturbation of vowel articulations by consonantal context: An acoustical study." Journal of Speech and Hearing Research, $6,111-28$.

Strange, W. and Shafer, V. 2008. "Speech perception in second language learners." In Hansen-Edwards, J. and Zampini, M., (eds) Phonology and Second Language Acquisition. Philadelphia: Johns Benjamin Publishing Company, 153-191.

Thompson, I. 1991. "Foreign accents revisited: The English pronunciation of Russian immigrants." Language Learning, 41, 177-204.

Wright, R. 2003. "Factors of lexical competition in vowel articulation." In Local, J., Ogden, R., and Temple, R. (eds) Papers in Laboratory Phonology VI: Phonetic Interpretation. Cambridge: Cambridge University Press, 75-87.

Yavas, M. 2011. Applied English Phonology. $2^{\text {nd }}$ Edition. Wiley-Blackwell Publishing. 


\section{APPENDICES: Appendix A}

\begin{tabular}{|l|l|l|l|l|}
\hline Participants & Gender & Age & Birth Place & $\begin{array}{l}\text { Age at Learning } \\
\text { English }\end{array}$ \\
\hline M1 & Female & 54 & North Carolina & native language \\
\hline M2 & Male & 50 & New Jersey & native language \\
\hline M3 & Female & 30 & North Carolina & native language \\
\hline M4 & Male & 60 & Tennessee & native language \\
\hline M5 & Male & 31 & New Jersey & native language \\
\hline M6 & Male & 33 & Pennsylvania & native language \\
\hline M7 & Female & 31 & New York & native language \\
\hline M8 & Female & 27 & North Carolina & native language \\
\hline M9 & Male & 33 & North Carolina & native language \\
\hline M10 & Female & 60 & Maryland & native language \\
\hline M11 & Male & 34 & Maryland & native language \\
\hline M12 & Male & 60 & Missouri & native language \\
\hline M13 & Male & 57 & South Carolina & native language \\
\hline M14 & Male & 29 & Georgia & native language \\
\hline M15 & Female & 50 & North Carolina & native language \\
\hline M16 & 19 & Florida & native language \\
\hline M17 & Female & 19 & New Jersey & native language \\
\hline M18 & Female & 19 & Florida & native language \\
\hline M19 & Male & 19 & Florida & native language \\
\hline M20 & Male & 18 & California & native language \\
\hline M21 & Female & 23 & Florida & native language \\
\hline M22 & Female & 24 & Florida & native language \\
\hline M23 & Female & 24 & Florida & native language \\
\hline M24 & Female & 23 & Florida & native language \\
\hline M25 & Male & 18 & California & native language \\
\hline
\end{tabular}




\section{Appendix B: Bilingual Demographics}

\begin{tabular}{|l|l|r|l|l|}
\hline E1 & Male & 25 & Florida & age 2 \\
\hline E2 & Female & 18 & Florida & age 2 \\
\hline E3 & Male & 23 & Florida & age 5 \\
\hline E4 & Female & 23 & Florida & age 3 \\
\hline E5 & Female & 22 & Florida & age 2 \\
\hline E6 & Male & 19 & Florida & age 5 \\
\hline E7 & Male & 18 & Florida & age 4 \\
\hline E8 & Male & 19 & Venezuela & age 6 \\
\hline E9 & Male & 20 & Florida & age 10 \\
\hline E10 & Female & 31 & Georgia & age 6 \\
\hline E11 & Male & 19 & Florida & age 5 \\
\hline E12 & Male & 20 & Puerto Rico & age 6 \\
\hline E13 & Female & 31 & Chile & age 9 \\
\hline E14 & Female & 18 & Venezuela & age 7 \\
\hline E15 & Male & Venezuela & age 2 \\
\hline E16 & Male & 18 & Florida & age 5 \\
\hline E17 & Male & 21 & Florida & age 7 \\
\hline E18 & 18 & Florida & age 3 \\
\hline E19 & Female & 18 & New York & age 5 \\
\hline E20 & Male & 19 & Florida & age 2 \\
\hline E21 & Male & 18 & Florida & age 5 \\
\hline E22 & Male & 18 & Florida & age 5 \\
\hline E23 & Male & 20 & Cuba & age 5 \\
\hline E24 & Male & 26 & Cuba & age 2 \\
\hline E25 & Male & 30 & Florida & age 5 \\
\hline & Male & & \\
\hline
\end{tabular}




\section{Appendix C: Late Bilingual Demographics}

\begin{tabular}{|l|l|r|l|l|}
\hline L1 & Female & 38 & Argentina & Age 24 \\
\hline L2 & & 48 & Dominican Republic & Age 16 \\
\hline L3 & Female & 36 & Argentina & Age 16 \\
\hline L4 & Female & 45 & Cuba & Age 15 \\
\hline L5 & Female & 22 & Spain & Age 16 \\
\hline L6 & Male & 26 & Chile & Age 18 \\
\hline L7 & Male & 37 & Cuba & Age 24 \\
\hline L8 & Female & 18 & Cuba & Age 15 \\
\hline L9 & Male & 50 & Cuba & Age 31 \\
\hline L10 & Male & 20 & Spain & Age 18 \\
\hline L11 & Female & 35 & Spain & Age 16 \\
\hline L12 & Female & 34 & Cuba & Age 15 \\
\hline L13 & Female & 24 & Venezuela & Age 23 \\
\hline L14 & Female & 25 & Cuba & Age 17 \\
\hline L15 & Male & 20 & Puerto Rico & Age 16 \\
\hline L16 & Male & 58 & Puerto Rico & Age 20 \\
\hline L17 & Female & 60 & Puerto Rico & Age 22 \\
\hline L18 & Male & 52 & Cuba & Age 36 \\
\hline L19 & Female & 19 & Venezuela & Age 15 \\
\hline L20 & Male & 24 & Cuba & Age 18 \\
\hline L21 & Female & 50 & Cuba & Age 25 \\
\hline L22 & Female & 35 & Cuba & Age 19 \\
\hline L23 & Female & 23 & Venezuela & Age 15 \\
\hline L24 & Female & 33 & Peru & Age 19 \\
\hline L25 & Female & 43 & Cuba & Age 24 \\
\hline & Male & & & \\
\hline
\end{tabular}




\section{Appendix D: Instrument}

\section{Experiment I:}

\section{A) Plural Morphemes:}

1. My nieces talk for hours.

2. These crutches take some getting used to.

3. Three judges took a vote.

4. Their noses tickled from the smoke.

5. These sashes tie in the front.

6. Hot sausages taste the best.

\section{B) Possessive Morpheme}

1. Marsha's talent is juggling.

2. Asia's territory is vast.

3. The judge's table was messy.

4. Lisa's twin looks just like her.

5. Sasha's teacher is German.

6. My niece's team won the game.

\section{C) Word-final Endings}

1. A ninja tiptoes in the dark

2. A trip to Russia takes money.

3. You use a hookah to take in smoke.

4. Wear a toga to the party.

5. The tuba takes strength to play.

6. A sofa takes two people to lift it. 


\section{Experiment II:}

\section{A) Deletable Schwas}

1. Don't say opera, say concert.

2. Don't say imaginative, say creative.

3. Don't say principal, say first.

4. Don't say testament, say document.

5. Don't say general, say usual.

6. Don’t say probably, say maybe.

B) Non-deletable Schwas

1. Don't say imagination, say creativity.

2. Don't say principality, say town.

3. Don't say operatic, say theatrical.

4. Don't say probability, say chance.

5. Don't say generality, say norm.

6. Don't say testimony, say account. 
Appendix E: Means and Standard Deviations for F1 values by place of articulation

\begin{tabular}{|c|c|c|}
\hline Group & Mean in Hz. & Standard Deviation in \\
\hline Monolinguals & & \\
a) post-labial F1 & 491.76 & 53.407 \\
b) post-dorsal F1 & 502.72 & 52.523 \\
c) post-coronal F1 & 474.80 & 50.785 \\
\hline Early bilinguals & & 53.825 \\
a) post-labial & 487.24 & 60.985 \\
b) post-dorsal & 500.16 & 62.312 \\
c) post-coronal & 479.28 & 65.960 \\
\hline Late bilinguals & & 49.310 \\
a) post-labial & 515.45 & 46.239 \\
b) post-dorsal & 527.91 & \\
c) post-coronal & 499.27 & \\
\hline
\end{tabular}


Appendix F: Means and standard deviations for F2-F1 values by place of articulation

\begin{tabular}{|c|c|c|}
\hline Group & Mean in Hz. & $\begin{array}{l}\text { Standard Deviation in } \\
\text { Hz. }\end{array}$ \\
\hline Mvonolinguals & 1185.44 & 179.100 \\
Avg postdorsal F2-F1 & 1222.44 & 142.730 \\
Avg postcoronal F2-F1 & 1348.84 & 101.211 \\
\hline Early bilinguals & & 199.364 \\
Avg postlabial F2-F1 & 1049.16 & 172.537 \\
Avg postdorsal F2-F1 & 1127.44 & 168.715 \\
Avg postcoronal F2-F1 & 1299.80 & 198.009 \\
\hline Late bilinguals & 1227.91 & 237.315 \\
Avg postlabial F2-F1 & 991.18 & 279.666 \\
Avg postdorsal F2-F1 & 1090.64 & \\
Avg postcoronal F2-F1 & & \\
\hline
\end{tabular}

